\title{
NON-VIRAL REPROGRAMMING OF HUMAN NUCLEUS PULPOSUS CELLS WITH FOXF1 VIA EXTRACELLULAR VESICLE DELIVERY: AN IN VITRO AND IN VIVO STUDY
}

\author{
S. Tang ${ }^{1}$, A. Salazar-Puerta ${ }^{1}$, J. Richards ${ }^{1}$, S. Khan'르, J.A. Hoyland ${ }^{3,4}$, D. Gallego-Perez ${ }^{1}$, B. Walter ${ }^{1}$, \\ N. Higuita-Castro ${ }^{1, \S}$ and D. Purmessur ${ }^{1, \S, *}$
}

\author{
${ }^{1}$ Department of Biomedical Engineering, The Ohio State University, Columbus, OH, USA \\ ${ }^{2}$ Department of Orthopedics, The Ohio State University Wexner Medical Center, Columbus, OH, USA \\ ${ }^{3}$ Division of Cell Matrix Biology and Regenerative Medicine, School of Biological Sciences, \\ The University of Manchester, Manchester, UK \\ ${ }^{4}$ NIHR Manchester Musculoskeletal Biomedical Research Centre, Manchester University, \\ NHS Foundation Trust, Manchester Academic Health Science Centre, Manchester, UK \\ $\S$ These authors contributed equally to this work
}

\begin{abstract}
Intervertebral disc (IVD) degeneration is characterized by decreased cellularity and proteoglycan synthesis and increased inflammation, catabolism, and neural/vascular ingrowth. Regenerative methods for IVD degeneration are largely cell-therapy-based or involve viral vectors, which are associated with mutagenesis and undesired immune responses. The present study used bulk electroporation and engineered extracellular vesicles (EVs) to deliver forkhead-box F1 (FOXF1) mRNA to degenerate human nucleus pulposus (NP) cells as a minimally invasive therapeutic strategy for IVD regeneration. Bulk electroporation was used to investigate FOXF1 effects on human NP cells during a 4-week culture in 3D agarose constructs. Engineered EV delivery of FOXF1 into human IVD cells in monolayer was determined, with subsequent in vivo validation in a pilot mouse IVD puncture model. FOXF1 transfection significantly altered gene expression by upregulating healthy NP markers [FOXF1, keratin 19 (KRT19)], decreasing inflammatory cytokines [interleukin (IL)-1 $\beta$, -6], catabolic enzymes [metalloproteinase 13 (MMP13)] and nerve growth factor (NGF), with significant increases in glycosaminoglycan accumulation in human NP cells. Engineered EVs loaded with FOXF1 demonstrated successful encapsulation of FOXF1 cargo and effective uptake by human NP cells cultured in monolayer. Injection of FOXF1-loaded EVs into the mouse IVD in vivo resulted in a significant upregulation of FOXF1 and Brachyury, compared to controls at $7 \mathrm{~d}$ post-injection, with no evidence of cytotoxicity. This is the first study to demonstrate non-viral delivery of FOXF1 and reprogramming of human NP cells in vitro and mouse IVD cells in vivo. This strategy represents a non-addictive approach for treating IVD degeneration and associated back pain.
\end{abstract}

Keywords: Intervertebral disc degeneration, low-back pain, cellular reprogramming, engineered extracellular vesicles, transcription factor, electroporation, FOXF1, regeneration.

*Address for correspondence: Devina Purmessur, PhD, 3155 Biomedical and Materials Engineering Complex, 140 W. $19^{\text {th }}$ Ave, Columbus, OH 43210, USA.

Telephone number: +1 6142921625 Email: Devina.Purmessur@osumc.edu

Copyright policy: This article is distributed in accordance with Creative Commons Attribution Licence (http://creativecommons.org/licenses/by-sa/4.0/).

\begin{tabular}{|c|c|c|c|}
\hline & List of Abbreviations & DMMB & dimethylmethylene blue \\
\hline & & ECM & extracellular matrix \\
\hline ACAN & aggrecan & EVs & extracellular vesicles \\
\hline $\mathrm{AF}$ & annulus fibrosus & FBS & fetal bovine serum \\
\hline CEP & cartilage end plate & FOXF1 & forkhead-box F1 (human) \\
\hline CHTN & Cooperative Human Tissue Network & Foxf1 & forkhead-box f1 (mouse) \\
\hline COL2 & collagen type II & GAG & glycosaminoglycan \\
\hline DBP & discogenic back pain & GDF & growth and differentiation factor \\
\hline DMEM & Dulbecco's modified Eagle's medium & KRT19 & keratin 19 \\
\hline
\end{tabular}


IL

IVD

LBP

MMP

MSCs

NGF

NP

pCMV6

PBS

PMEF

$\mathrm{P} / \mathrm{S}$

SOX9

TNF- $\alpha$ interleukin

intervertebral disc

low-back pain

matrix metalloproteinase

mesenchymal stem cells

nerve growth factor

nucleus pulposus

pCMV6 sham vector control

phosphate-buffered saline

primary mouse embryonic fibroblast

penicillin/streptomycin

SRY-box transcription factor 9

tumor necrosis factor alpha

\section{Introduction}

Chronic LBP is the leading cause of disability worldwide, affecting 70-80\% of the population during their lifetime and many studies have demonstrated IVD degeneration as being a leading cause (Global Burden of Disease Study 2013 Collaborators, 2015; Katz, 2006; Malik et al., 2013; Schwarzer et al., 1995). Furthermore, the economic burden of LBP exceeds $\$ 100$ billion annually in the USA alone due to the loss of workdays, use of costly interventions, and its role in the growing opioid epidemic (Balagué et al., 2012; Deyo et al., 2015; Katz, 2006). The healthy IVD is avascular and aneural, composed of a core of gelatinous hydrophilic proteoglycans in the central NP encased by concentric collagen I rings that form the AF. The IVD is contained cranially and caudally by the CEPs, which supply nutrients to the disc (Ghosh, 1988). The NP is considered to be the "metabolic engine" of the IVD as it functions to maintain the hydrated core through synthesis of ACAN and COL2, whilst providing load distribution and compressive force absorption (Trout et al., 1982a; 1982b). During IVD degeneration, the NP is characterized by decreased cellularity and proteoglycan synthesis, increased catabolism, along with increases in cell senescence, pro-inflammatory factors, and neural/vascular invasion (Freemont, 2008; Vo et al., 2016). Specifically, studies have demonstrated that degenerated IVDs have decreased ACAN/GAG and COL2 synthesis as well as increased matrix MMPs, proinflammatory cytokines such as IL-1 $\beta$, IL-6, TNF- $\alpha$, along with increased NGF (Lama et al., 2018; Le Maitre et al., 2007a; Purmessur et al., 2008; Smith et al., 2011). These changes lead to depressurization of the NP that alters IVD structure and function, resulting in spinal instability.

Many clinical interventions exist for LBP including analgesics, physical therapy, and surgical treatment. However, these interventions only alleviate symptoms while failing to treat the underlying disease pathology (Zhao et al., 2019). Therefore, there is a need for biological interventions that target the early stages of IVD degeneration to reduce/inhibit the degeneration process while also limiting the symptoms of pain. Several potential biological strategies, including the injection of exogenous growth factors (Sobajima et al., 2004), and cell therapies [e.g., MSCs] have been investigated to promote regeneration and reduce inflammation (Loibl et al., 2019; Vadalà et al., 2016). However, several challenges limit their therapeutic potential. For example, growth-factor-based approaches often have a transient therapeutic effect and require repeated dosing. Cell-therapy-based approaches are limited by cell source and long-term efficacy due to poor cell survival in the harsh IVD environment as well as the potential risk for immunogenicity and tumorigenicity (Karagiannis and Yamanaka, 2014; Loibl et al., 2019; Vadalà et al., 2016). As such, cellular reprogramming may be a potential novel therapeutic approach for treatment of IVD degeneration.

Direct cell reprogramming is an alternative biological strategy that has shown promise in other tissues as it addresses many of the limitations of the therapies described above. This approach allows adult somatic cells, which are a widely available cell source, to be transdifferentiated into the desired cell type with the aid of transcription factors, while bypassing the pluripotent state (Karagiannis and Yamanaka, 2014; Takahashi and Yamanaka, 2006). In the present study, reprogramming is defined as reverting somatic diseased cells into a healthy state. Viral vectors are most commonly used for gene delivery due to their simplicity and reproducibility of transfection; however, viral gene delivery has significantly limited clinical application due to the potential for immunogenicity, insertional mutagenesis, and capsid size constraints (Cao et al., 2010; Okita et al., 2008; Sobajima et al., 2004). To circumvent these hurdles, minimally invasive nonviral gene delivery systems that allow direct cell reprogramming through transcription factors are potential approaches that would eliminate much of the potential risks associated with viral-based gene transfer. Transcription factor FOXF1 has been identified as a potential candidate.

FOXF1 is part of a family of genes involved in the regulation of cell differentiation, growth, and proliferation (Tuteja and Kaestner, 2007). It has recently been identified as a healthy-NP-specific marker with reduced expression during degeneration (Richardson et al., 2017a; Risbud et al., 2015). Deletion of FOX gene clusters in transgenic mouse models leads to spinal and vertebral abnormalities (Stankiewicz et al., 2009). In addition, FOXF1 promotes tissue repair in other organs such as lungs and liver (Bolte et al., 2017; Flood et al., 2019). In a previous study, the developmental transcription factor Brachyury was successful in reprogramming human NP cells from degenerate and painful IVDs to a healthy immature NP-like phenotype (Tang et al., 2019). Thus, FOXF1 could be an additional promising candidate to be explored.

In addition to FOXF1, a mechanism is required for non-viral delivery of the transcription factor into IVD cells in a minimally invasive manner and, 
thus, the use of engineered EVs is proposed in the present study. EVs are composed of a lipid bilayer comprising transmembrane and cytosolic proteins, DNA fragments, and RNAs that are protected from enzymatic degradation (Valadi et al., 2007). EVs can be classified according to their size, content, and mechanism of generation into multivesicular bodies, exosomes, or apoptotic bodies and play an important role in several processes, including intracellular communication, proliferation, and differentiation (de Jong et al., 2012; Mulcahy et al., 2014). Therefore, they can interact with target cells and release their contents into the cytosol, allowing alteration of gene and protein expression in the recipient cell (Stoorvogel et al., 2002). Consequently, $\mathrm{EVs}$ are ideal candidates for gene therapy since they display non-immunogenic characteristics (Ha et al., 2016; O'Brien et al., 2020). Gallego-Perez et al. (2017) demonstrated the feasibility of using EVs loaded with a specific transcription factor transcript to achieve direct cell reprogramming of fibroblasts into induced endothelium or induced neurons. These features highlight the potential of engineered EVs to function as a therapeutic delivery system that can replace the use of viral vectors and overcome the caveats associated with viral delivery.

Therefore, the main goal of the present study was to examine the reprogramming potential of non-viral delivery of transcription factors using engineered EVs. The first objective was to examine the effects of FOXF1 on human NP cells derived from autopsy (mildly-degenerate) and surgery (painfuldegenerate) through non-viral bulk transfection with cells cultured in a $3 \mathrm{D}$ in vitro agarose culture model. The study hypothesis was that FOXF1 mRNA transcripts could reprogram human NP cells from autopsy and surgery into a healthy phenotype characterized by increases in GAG accumulation, and decreases in inflammatory, catabolic and pain-associated factors. The second objective was to examine the delivery of engineered NP-derived FOXF1-loaded EVs to human NP cells in a monolayer culture, with subsequent validation of delivery and FOXF1 expression in a short-term pilot in vivo mouse disc puncture model. The study hypothesis was that human NP cells cultured in monolayer will uptake NP-generated FOXF1-loaded EVs and demonstrate increased expression of FOXF1 in vitro. Also, these FOXF1-loaded EVs could be delivered to the IVD in vivo in a mouse IVD injury model with up-regulation of the foxf1 transcript.

\section{Materials and Methods}

\section{In vitro reprogramming of human NP cells by bulk electroporation of FOXF1 (Fig. 1)}

Cell isolation and expansion from human IVD tissue

Lumbar human spines were obtained from autopsy ( $n=5,19-58$ years old donors) through the CHTN (Institutional IRB exemption) within $24 \mathrm{~h}$ post-mortem. IVDs were isolated and graded by three independent investigators according to the Thompson scale and grades were averaged (Table 1: human samples) (Thompson et al., 1990). NP tissue from autopsy was dissected and NP cells isolated as previously described (Tang et al., 2019). Surgical NP tissue from patients undergoing microdiscectomy or lumbar fusion with degenerate IVDs ( $n=5$, 19-60 years old donors), as referenced by magnetic resonance imaging, were obtained from The Ohio State University Wexner Medical Center (IRB:2015H0385). Post dissection, cells were isolated from autopsy and surgical NP tissue using $0.03 \mathrm{~g} / \mathrm{mL}$ protease (Sigma-Aldrich, Cat: P5147-1G) in digestion medium [DMEM (Corning, Manassas, VA, USA, Cat: $10-013-\mathrm{CV}), 4.5 \mathrm{~g} / \mathrm{mL}$ glucose, $1 \% \mathrm{P} / \mathrm{S}, 0.5 \%$ Fungizone] for $1 \mathrm{~h}$ at $37^{\circ} \mathrm{C}$, followed by treatment with $0.03 \mathrm{~g} / 15 \mathrm{~mL}$ collagenase II (Thermo Fisher Scientific, Cat: 17101015$)$ for $4 \mathrm{~h}$ at $37^{\circ} \mathrm{C}$. The tissue digest was strained through a $70 \mu \mathrm{m}$ cell strainer to remove cellular debris and cells were plated for expansion (Tang et al., 2019). To assess the effects of FOXF1 on mild to moderate IVD degeneration, IVDs from autopsy with averaged Thompson grades of 1.5-3 were selected, while surgical cells from patients undergoing surgery for LBP represented the painful IVD degeneration group. Autopsy and surgical NP cells pre-transfection were expanded in disc cell medium (DMEM, $4.5 \mathrm{~g} / \mathrm{mL}$ glucose, $10 \%$ FBS, $1 \%$ $\mathrm{P} / \mathrm{S}, 0.5 \%$ Fungizone, $50 \mu \mathrm{g} / \mathrm{mL}$ freshly prepared ascorbic acid) in standard culture conditions (5\% $\mathrm{CO}_{2}, 37^{\circ} \mathrm{C}$ ). Medium was changed every $3 \mathrm{~d}$ until $80 \%$ confluency, when the cells were used for downstream transfection (Passage $=$ P2).

\section{FOXF1 transcription factor plasmid expansion}

A FOXF1 gene in pCMV6-AC-GFP vector, with antibiotic selection marker ampicillin, was obtained from OriGene Technologies, Rockville, MD, USA (Cat: RG218259, reference sequence from NIH: NM_001451, Human Tagged ORF Clone). Vector pCMV6 plasmids were also obtained and used as sham empty vector controls (Origene, Cat: PS100001) (Table 2: plasmids). As described previously (Tang et al., 2019), FOXF1 plasmids were transformed into DH5 $\alpha$ Escherichia coli (E.coli) following heat shock and incubated with S.O.C. medium (2\% tryptone, $0.5 \%$ yeast extract, $10 \mathrm{mM} \mathrm{NaCl}, 2.5 \mathrm{mM} \mathrm{KCl}, 10 \mathrm{mM}$ $\mathrm{MgCl}_{2}, 10 \mathrm{mM} \mathrm{MgSO}_{4^{\prime}} 20 \mathrm{mM}$ glucose $)$ for $1 \mathrm{~h}\left(37^{\circ} \mathrm{C}\right.$, $225 \mathrm{rpm})$. Then, bacterial cells were cultured on solid agar (4\% agar in lysogeny broth, Thermo Fisher Scientific, Cat: BP1425-500) for $24 \mathrm{~h}$ with ampicillin $(100 \mu \mathrm{g} / \mathrm{mL})$ and selectively cultured in small and large liquid cultures for $24 \mathrm{~h}$. Next, plasmids were isolated from the selectively expanded E.coli using a ZymoPure II Plasmid Midiprep Kit (Zymo Research, Irvine, CA, USA, Cat: 4201) per manufacturer protocol and quantified using a Nanodrop 2000c Spectrophotometer. 
Table 1. Human autopsy and surgical specimen demographics.

\begin{tabular}{|c|c|c|c|c|c|c|c|c|}
\hline \multicolumn{5}{|c|}{ Autopsy samples } & \multicolumn{4}{|c|}{ Surgical samples } \\
\hline ID & Sex & $\begin{array}{c}\text { Age } \\
\text { (years) }\end{array}$ & Level & $\begin{array}{c}\text { Averaged } \\
\text { grade }\end{array}$ & ID & Sex & $\begin{array}{c}\text { Age } \\
\text { (years) }\end{array}$ & Level \\
\hline $\mathrm{Hu}-4^{*}$ & Female & 49 & L2-L3 & 2.5 & Hs-2* & Male & 26 & L5-S1 \\
\hline $\mathrm{Hu}-6^{*}$ & Male & 45 & L2-L3 & 3 & Hs-11* & Male & 28 & L5-S1 \\
\hline $\mathrm{Hu}-7^{*}$ & Female & 56 & L2-L3 & 2.5 & Hs-29* & Female & 70 & L5-S1 \\
\hline $\mathrm{Hu}-9^{*}$ & Female & 58 & L4-L5 & 2.5 & Hs-34* & Female & 19 & L5-S1 \\
\hline $\mathrm{Hu}-13^{\wedge}$ & Female & 30 & L4-L5 & 2.5 & Hs-39* & Male & 60 & L5-S1 \\
\hline $\mathrm{Hu}-15^{\wedge}$ & Female & 59 & L1-L2 & 3 & \multirow{3}{*}{\multicolumn{4}{|c|}{$\begin{array}{l}*=\text { samples used in objective } 1 \\
\wedge=\text { samples used in objective } 2\end{array}$}} \\
\hline $\mathrm{Hu}-16^{* \wedge}$ & Female & 19 & L1-L2 & 1.5 & & & & \\
\hline $\mathrm{Hu}-17^{\wedge}$ & Male & 39 & L4-L5 & 3.25 & & & & \\
\hline
\end{tabular}

Table 2. OriGene technologies plasmid and antibiotic details.

\begin{tabular}{|c|c|c|c|c|c|}
\hline Name & $\begin{array}{c}\text { Catalog } \\
\text { number }\end{array}$ & Ref sequence from NIH & Species & Antibiotic resistance & Vector \\
\hline FOXF1 & RG218259 & NM_001451 & Human & Ampicillin $(100 \mu \mathrm{g} / \mathrm{mL})$ & pCMV6-AC-GFP \\
\hline Foxf1 & MR225056 & NM_010426 & Mouse & Kanamycin $(25 \mu \mathrm{g} / \mathrm{mL})$ & pCMV6-Entry \\
\hline pCMV6 & PS100001 & NA & NA & Kanamycin $(25 \mu \mathrm{g} / \mathrm{mL})$ & pCMV6-Entry \\
\hline
\end{tabular}

\section{FOXF1 transfection}

Human NP cells were expanded to $80 \%$ confluency, as previously described (Tang et al., 2019). Bulk transfection was performed using the Neon Transfection System MPK5000. Previously isolated FOXF1 and pCMV6 plasmids were mixed with $\mathrm{R}$ buffer $(0.05 \mu \mathrm{g} \mathrm{DNA} / \mu \mathrm{L})$ and transfected $(1,425 \mathrm{~V}$, $30 \mathrm{~ms}, 1$ pulse) into $1 \times 10^{6}$ cells/transfection, according the following groups (multiple transfections per experimental group): NP cells from autopsy transfected with FOXF1 (autopsy FOXF1), NP cells from surgery transfected with FOXF1 (surgical FOXF1), NP cells transfected with pCMV6 sham vector (autopsy pCMV6, surgical pCMV6). Cells were plated in T-175 cell culture flasks for expansion in antibiotic-free medium (DMEM with $4.5 \mathrm{~g} / \mathrm{mL}$ glucose, $10 \% \mathrm{FBS}, 50 \mu \mathrm{g} / \mathrm{mL}$ freshly prepared ascorbic acid) for $48 \mathrm{~h}$ before switching to expansion in disc cell medium, as previously described (Tang et al., 2019).

\section{$3 D$ agarose culture}

Transfected NP cells at $~ 80 \%$ confluency were washed with sterile $1 \times$ PBS, trypsinized, and suspended at $40 \times 10^{6}$ cells $/ \mathrm{mL}$ in disc cell medium (Mauck et al., 2002). As described, a $52 \times 32 \mathrm{~mm}$ rectangular construct was made using $4 \mathrm{~mm}$-thick sterile silicone sheets (Tang et al., 2019). Cells suspended in medium were mixed with equal amounts of $4 \%$ biological grade agarose (Amresco VWR, Solon, OH, USA, Cat: J234) at $50{ }^{\circ} \mathrm{C}$ to create a $2 \%$ agarose mixture of $20 \times 10^{6}$ cells $/ \mathrm{mL}$. The mixture was quickly homogenized by pipetting, added to the silicone mold sandwiched between two glass plates and allowed to solidify for $10 \mathrm{~min}$ at room temperature. Glass plates were removed, and $8 \mathrm{~mm}$ diameter sterile biopsy punches were used to create $8 \times 4 \mathrm{~mm}$ tall cylindrical constructs from the solidified cell-seeded agarose. Individual constructs were cultured in $2 \mathrm{~mL}$ of disc cell medium in 24well cell-repellant culture plates and medium was changed 3 times a week (Tang et al., 2019). Dependent variables including cell viability, gene expression and proteoglycan accumulation were assessed at day 0 , week 2 , and week 4 post agarose culture.

\section{Cell viability}

Cell-agarose constructs were divided into two halves, washed with $1 \times$ PBS and incubated in $700 \mu \mathrm{L}$ live/ dead solution (Thermo Fisher Scientific, Cat: L3224) for $18 \mathrm{~min}$ to stain live and dead cells using green fluorescent calcein-AM $(4 \mathrm{mM})$ and red fluorescent ethidium-homodimer-1 ( $2 \mathrm{mM})$, respectively. Then, samples were washed with $1 \times$ PBS to remove the residual dye and imaged under fluorescence imaging using a Nikon TiE microscope with a DS-Qi2 camera (Nikon Instruments Inc., Melville, NY, USA). 10× and $4 \times$ cross-sectional images were taken of each gel with $10 \times$ images used for automatized quantification of cell viability (percentage live cells $=\mathrm{s}$ number of live cells over total cells) using MIPAR Image Analysis Software (Tang et al., 2019).

\section{Gene expression}

mRNA was isolated from the cells seeded in the constructs using the TRIzol Plus RNA Purification Kit (Thermo Fisher Scientific, Cat: 1218355), with the entire cell-agarose gel complex directly digested in TRIzol, and cDNA synthesized using the Maxima H Minus Mastermix (Thermo Fisher Scientific, Cat: 
Table 3. TaqMan gene expression primer details.

\begin{tabular}{|c|c|c|}
\hline Category & Target gene & Assay ID \\
\hline Control & $18 S$ & $4333760 \mathrm{~F}$ \\
\hline \multirow{4}{*}{ Healthy NP makers } & Brachyury & Hs00610080_m1 (human), Mm00436877_m1 (mouse) \\
\hline & FOXF1 & Hs00230962_m1(human), Mm00487497_m1(mouse) \\
\hline & KRT19 & Hs00761767_s1 \\
\hline & SOX9 & Hs01107818_m1 \\
\hline \multirow{3}{*}{ Inflammatory cytokines } & IL-1 $\beta$ & Hs00174097_m1 \\
\hline & IL6 & Hs00174131_m1 \\
\hline & TNF $\alpha$ & Hs01113624_g1 \\
\hline Nerve growth & NGF & Hs00171458_m1 \\
\hline Matrix degrading enzymes & MMP13 & Hs00233992_m1 \\
\hline \multirow{2}{*}{ Matrix genes } & COL2 & Hs00264051_m1 \\
\hline & $A C A N$ & Hs00153936_m1 \\
\hline
\end{tabular}

M1662) per manufacturer's protocol (Tang et al., 2019). RT-qPCR was run on 384-well plates with $15 \mathrm{ng}$ of cDNA per reaction using TaqMan Universal Master Mix II (Thermo Fisher Scientific, Cat: 4440049) and TaqMan primers (Table 3). Data were analyzed using the comparative $2^{-\Delta \Delta \mathrm{Ct}}$ method normalized to the housekeeping gene $18 \mathrm{~S}$ and experimental pCMV6 vector controls (Livak and Schmittgen, 2001).

\section{Proteoglycan/GAG content}

Constructs were lyophilized and digested in $1 \mathrm{~mL}$ of Proteinase K (Roche, Indianapolis, IN, USA, Cat: 03115828001) working solution (1 : 200 Proteinase K to ultra-pure distilled water and $10 \mathrm{mM}$ Tris- $\mathrm{HCl}$ ) for $20 \mathrm{~h}$ (on a shaker at $250 \mathrm{rpm}, 60^{\circ} \mathrm{C}$ ). GAG content was measured in a 96-well plate by a colorimetric DMMB (Sigma-Aldrich, Cat: 341088), using chondroitin sulfate (Sigma-Aldrich, Cat: c4384) for the standard curve. Plates were read at $530 \mathrm{~nm}$ wavelength on an Enspire Plate Reader. GAG content was normalized to DNA content using the Sigma-Aldrich DNA Quantification Kit (Cat: DNAQF).

\section{Delivery of FOXF1 to IVD cells in vitro and in vivo} through engineered EVs (Fig. 2)

FOXF1 transcription factor plasmid expansion

Human FOXF1 plasmids were generated as previously described for FOXF1 bulk transfection/ reprogramming studies. Mouse Foxf1 plasmids were obtained from Origene (Cat: MR225056, reference sequence NIH: NM_010426), expanded in E. coli presenting kanamycin $(25 \mu \mathrm{g} / \mathrm{mL})$ selectivity, isolated, and quantified.

\section{$N P$ and fibroblast cell expansion}

Human NP cells from autopsy $(n=4)$ (Table 1$)$ were expanded as described for FOXF1 bulk transfection/ reprogramming studies and pooled for downstream engineered EV generation and treatment of human diseased NP cells in vitro. PMEF from EMD Millipore (Burlington, MA, USA, Cat: PMEF HL) were expanded in DMEM, supplemented with
$10 \%$ FBS, $1 \%$ antibiotic-antimycotic 100× (GIBCO, Cat: 15240062), $1 \%$ non-essential amino acids 100× (GIBCO, Cat: 11140050), in standard conditions (5\% $\mathrm{CO}_{2}, 37^{\circ} \mathrm{C}$ ), until they reached $80-85 \%$ confluence for transfection.

\section{Engineered vesicle generation and isolation}

After expansion, human NP cells and PMEFs were resuspended at a final concentration of $1.0 \times 10^{6}$ cells in $100 \mu \mathrm{L}$ of electrolytic buffer per transfection group. FOXF1 and pCMV6 (sham) plasmids solutions were prepared at $0.05 \mu \mathrm{g} / \mu \mathrm{L}$ in an electrolytic buffer. Non-viral cell transfection of the plasmids was performed by bulk electroporation using the Neon Transfection System MPK5000 following manufacturer's instructions $(1,425 \mathrm{~V}, 30 \mathrm{~ms}$, 1 pulse) as described for FOXF1 bulk transfection/ reprogramming studies. After transfection, cells were cultured for $24 \mathrm{~h}$ in standard conditions with medium containing exosome-depleted FBS (GIBCO, Cat: A27208-01). To isolate EVs, culture medium was recollected $24 \mathrm{~h}$ after transfection and centrifuged at $2,000 \times g$ for $30 \mathrm{~min}$ at $4{ }^{\circ} \mathrm{C}$ to remove dead cells and debris, as previously reported (DuarteSanmiguel et al., 2020; Gallego-Perez et al., 2017). After centrifugation, the supernatant containing the EVs was transferred to a new tube and Total Exosome Isolation Reagent (Thermo Fisher Scientific) was added at a $1: 2$ ratio (exosome reagent : supernatant) and incubated at $4{ }^{\circ} \mathrm{C}$ overnight. Then, samples were centrifuged at $10,000 \times g$ for $1 \mathrm{~h}$ at $4{ }^{\circ} \mathrm{C}$. Engineered EVs were obtained and pellets were stored at $-80^{\circ} \mathrm{C}$ until characterization prior to use. EV concentration and size distribution were measured using Malvern NanoSight NS300 (ATA Scientific instruments). RT-qPCR on mRNA was performed on both the transfected cells and generated EVs to ensure successful transfection of FOXF1 into donor cells and packaging within the engineered EVs. For imaging purposes, EVs were labeled with a red fluorescent cell linker for membrane labeling (Sigma-Aldrich, Cat: PKH26GL-1KT) following manufacturer protocol. 
In vitro human NP cells and treatment with designer EVS Human NP cells $(n=4)$ were seeded in 24-well plates at 50,000 cells/well in standard disc cell medium $\left(37^{\circ} \mathrm{C}\right.$, $5 \% \mathrm{CO}_{2}$ ). Approximately $1.5 \times 10^{6} \mathrm{NP}$ cells were transfected to generate $6 \times 10^{10} \mathrm{EVs} / \mathrm{mL}$ to treat 50,000 $\mathrm{NP}$ cells in culture. After $24 \mathrm{~h}$, cells were washed with sterile $1 \times$ PBS and human NP-cell-derived FOXF1- or pCMV6-loaded EVs $\left(\sim 1 \times 10^{9} \mathrm{EVs}\right.$ resuspended in disc cell medium) were added to each well. Brightfield and fluorescent images of the cells were captured at $24 \mathrm{~h}, 48 \mathrm{~h}$, and $7 \mathrm{~d}$ post-transfection and overlaid to visualize uptake of engineered EVs stained with the PKH26 fluorescent (red) marker. Effective delivery of FOXF1 was assessed by quantification of FOXF1 expression at 2 and $7 \mathrm{~d}$ by RT-qPCR, as described for FOXF1 bulk transfection/reprogramming studies.

Pilot in vivo mouse lumbar disc puncture and designer EV injection

To assess engineered EV delivery of Foxf1 in vivo, a mouse lumbar IVD puncture model was used (IACUC\#2016A00000074-R). 15-week old male wildtype mice (The Jackson Laboratory, Sacramento,
CA, USA, Cat: C57BL/6J) were injected with $0.1 \mathrm{mg} /$ $\mathrm{kg}$ buprenorphine SR for post-operative pain management. Mice were anesthetized using $5 \%$ isoflurane and maintained under anesthesia (1.5$2.0 \%$ isoflurane) on a heating pad for the entire procedure ( $30 \mathrm{~min})$. A $40 \mathrm{~mm}$ diameter patch of fur was removed from the mouse abdomen and the skin was sterilized following 3 cycles of $70 \%$ isopropyl alcohol and betadine. A $1.5 \mathrm{~cm}$ left unilateral incision was made on the mouse abdomen and skin and organs pushed aside to reveal the lumbar spine and IVD as described in detail by Shi et al. (2018). Lumbar L4/L5, L5/L6, and L6/S1 discs were punctured with a $30 \mathrm{G}$ needle connected to a $10 \mu \mathrm{L}$ Hamilton syringe with a plastic stopper of $1 \mathrm{~mm}$ needle depth. The discs of each mouse were injected with $2 \mu \mathrm{L}$ of medicalgrade saline solution containing either no EVs (injury sham), FOXF1-loaded EVs or pCMV6-loaded EVs (vector control) derived from PMEFs ( $n=3$ per injury control). Post injection, the injury site was sutured by nylon sutures and the mice were sacrificed $7 \mathrm{~d}$ post-surgery. Whole mice IVDs (including NP, $\mathrm{AF}$, and endplates) were dissected and incubated

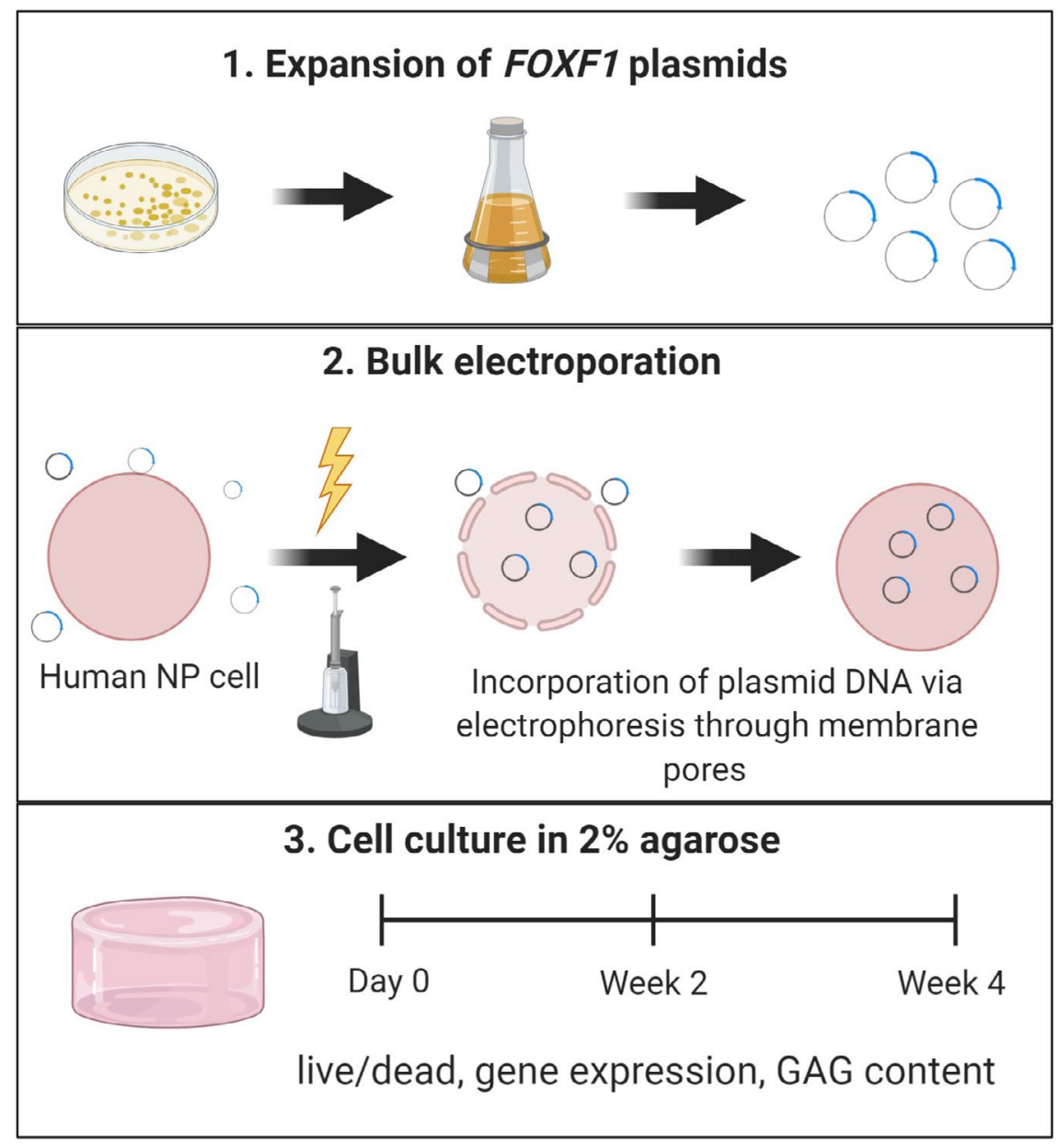

Fig 1. Schematic representation of in vitro reprogramming of human NP cells by bulk electroporation of FOXF1. (1) First FOXF1 plasmids were expanded in solid agarose culture followed by large culture and isolation of expanded plasmids. (2) Plasmids were suspended in solution with human NP cells and bulk-electroporated to induce transient membrane openings. Then, plasmids infiltrated the porous cell and were enclosed inside the cell. (3) Next, electroporated cells were seeded in a 3D $2 \%$ agarose culture for 4 weeks with dependent variables assessed at day 0 , week 2 , and week 4 . Illustration created with licensed BioRender.com software. 
with Hoechst and calcein-AM. Fluorescent images of the IVDs were captured to qualitatively assess cell viability. To quantify the success of delivery, RT-qPCR performed for FOXF1 and Brachyury was performed on the entire disc as described previously with relevant whole disc controls.

\section{Statistical analysis}

To compare differences between bulk transfection of FOXF1 vs. pCMV6 vector controls and FOXF1loaded EVs vs. pCMV6-loaded EVs, non-parametric, two-tailed, unpaired Mann-Whitney tests were performed for $\alpha=0.05$, with a Bonferroni correction for multiple comparisons. For in vivo mouse studies comparing gene expression in injury, pCMV6, and Foxf1 treatment groups, a one-way ANOVA was used followed by Tukey post-hoc test with $\alpha=0.05$.

\section{Results}

In vitro reprogramming of human NP cells by bulk electroporation of FOXF1

Cell viability

To access the viability of human NP cells in the 3D construct, a live/dead assay was used that stained live cells green (calcein-AM) and dead cells red (ethidium-homodimer). No significant differences in cell viability were observed for pCMV6- and FOXF1-transfected groups across the 4-week culture in autopsy and surgical NP cells, and all constructs maintained more than $90 \%$ viability (Fig. 3a,b).

Gene expression: phenotypic markers, inflammatory cytokines, NGF, matrix enzymes

RT-qPCR was used to quantify the relative fold change in gene expression of healthy NP markers, inflammatory cytokines, NGF, and matrix enzymes in human NP cells transfected with FOXF1, normalized to pCMV6-transfected control NP cells and the housekeeping gene 18S. All comparisonns discussed below are between FOXF1-treated and pCMV6 control.

The healthy NP marker FOXF1 was upregulated at all time points at day $0=2.35$-fold $(p=0.0159)$, week $2=1.64$-fold ( $p=0.0556)$, and week $4=2.03$ fold $(p=0.0079)$ in autopsy NP cells, while only significantly upregulated at day 0 (1.63-fold, $p=0.0493$ ) in surgical NP cells. Although no significant differences were found in Brachyury for autopsy NP cells, significant downregulation was observed at day 0 (-3.93-fold, $p=0.0079$ ) for surgical NP cells. KRT19

\section{Bulk electroporation of cells with FOXF1}

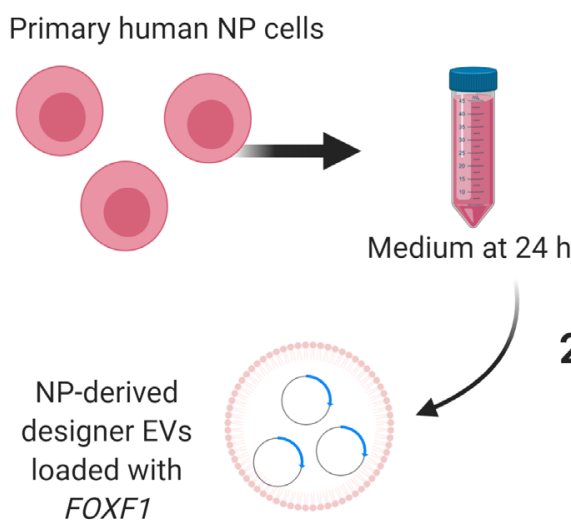

\section{EVs introduced to NP cells in monolayer well-plate}

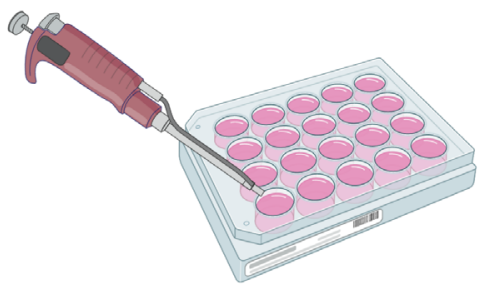

Primary mouse embryonic fibroblasts (PMEF)
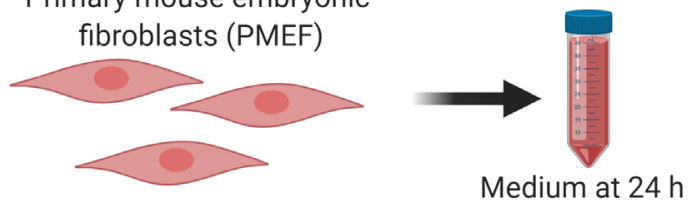

2. EV isolation

PMEF-derived designer EVs loaded with Foxf1

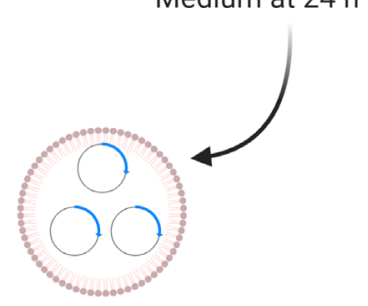

\section{EV injection into mouse lumbar IVD}

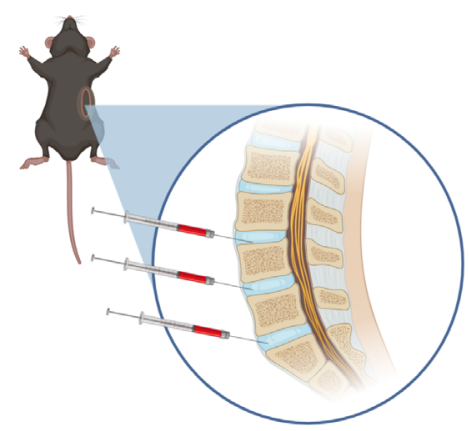

Fig 2. Schematic representation of delivery of FOXF1 to IVD cells in vitro and in vivo using engineered EVs. (1) First, human NP cells and mouse fibroblasts were transfected with FOXF1 respectively and medium was collected $24 \mathrm{~h}$ post-transfection. (2) EVs were isolated by ultracentrifugation and (3) cultured with NP cells in 24-well plates in vitro (human) or injected into mice L4/5, L5/6, L6/S1 discs after performing a left unilateral incision in vivo. Illustrations created with licensed BioRender.com software. 


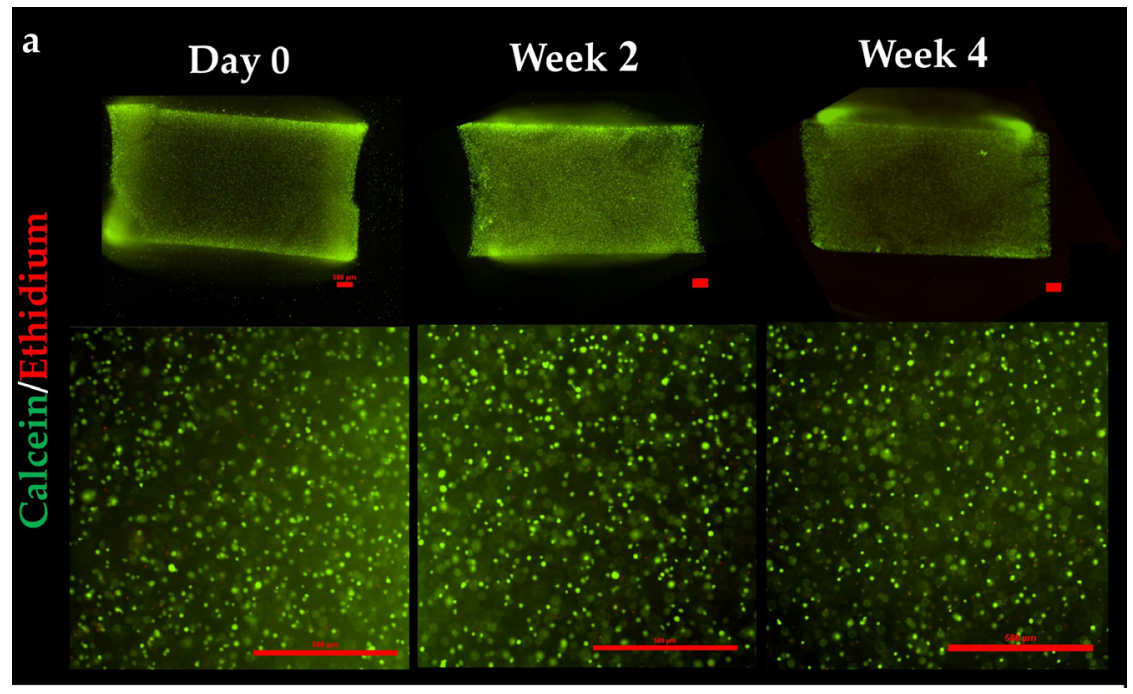

b

Autopsy cell viability

\section{Surgical cell viability}
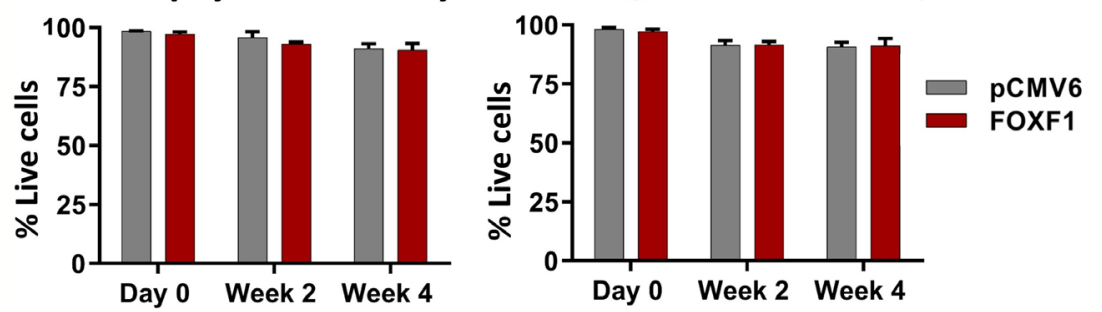

Fig 3. Cell viability of 3D gels. (a) Representative $4 \times$ (top) and 10× images (bottom) of calcein-AM (live) and ethidium-homodimer (dead) stained sagittal cryosections of cell-embedded 3D agarose gels at day 0 , week 2 and 4 weeks in culture (scale bar: $500 \mu \mathrm{m}$ ). Brightness of images adjusted equally for each image for better contrast. (b) Quantified cell viability based on number of live cells over total cells of respective FOXF1 and pCMV6 transfected groups for autopsy and surgical cells. No statistical differences were observed between groups.

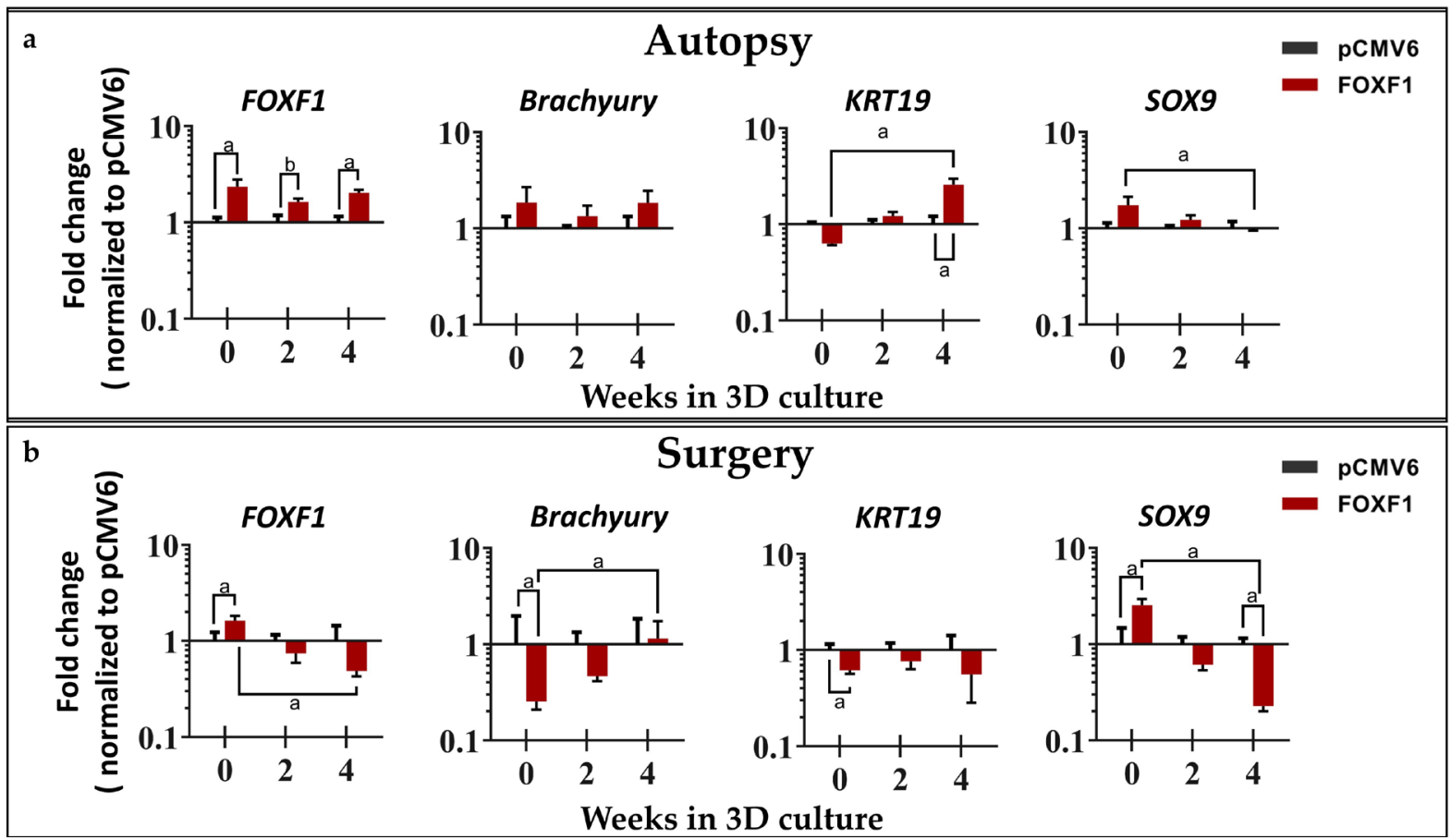

Fig 4. Phenotypic marker gene expression. FOXF1, Brachyury, KRT19, and SOX9 for (a) autopsy $(n=5)$ and (b) surgical human NP cells $(n=5)$ at 0,2 , and 4 weeks in 3D agarose culture normalized to pCMV6 controls and house-keeping gene $18 S$ ( ${ }^{\mathrm{a}} p<0.05,{ }^{\mathrm{b}} p=0.0556$ for FOXF1-treated NP cells when compared to pCMV6 controls). 


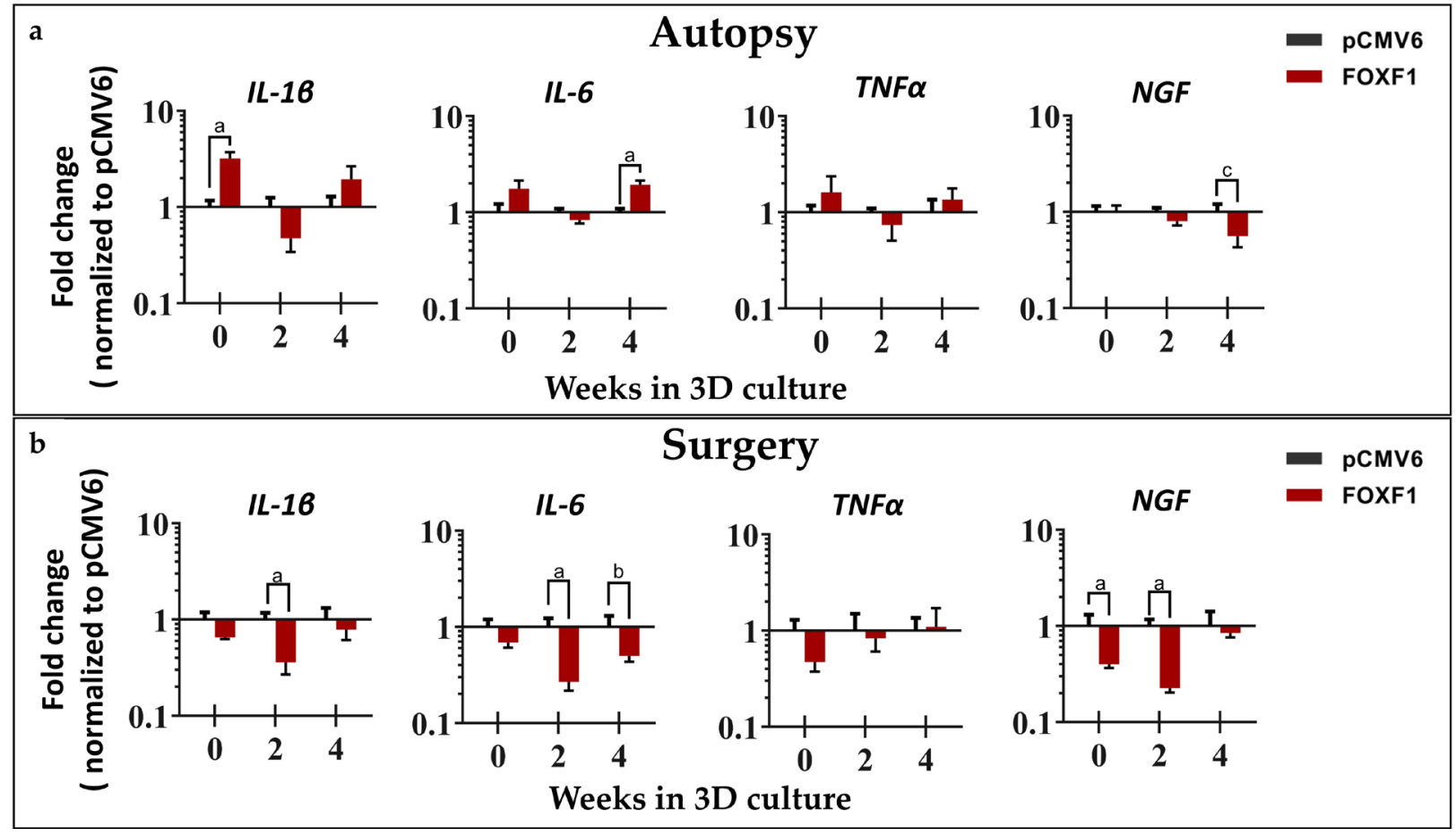

Fig 5. Inflammatory cytokine and NGF gene expression. $I L-1 \beta, I L-6, T N F-\alpha$ and NGF for (a) autopsy ( $n=5)$ and (b) surgical human NP cells $(n=5)$ at 0,2 , and 4 weeks in 3D agarose culture normalized to pCMV6 controls and house-keeping gene $18 S$ ( ${ }^{\mathrm{a}} p<0.05,{ }^{\mathrm{b}} p=0.0873$, and ${ }^{\mathrm{c}} p=0.079$ for FOXF1-treated NP cells when compared to pCMV6 controls).

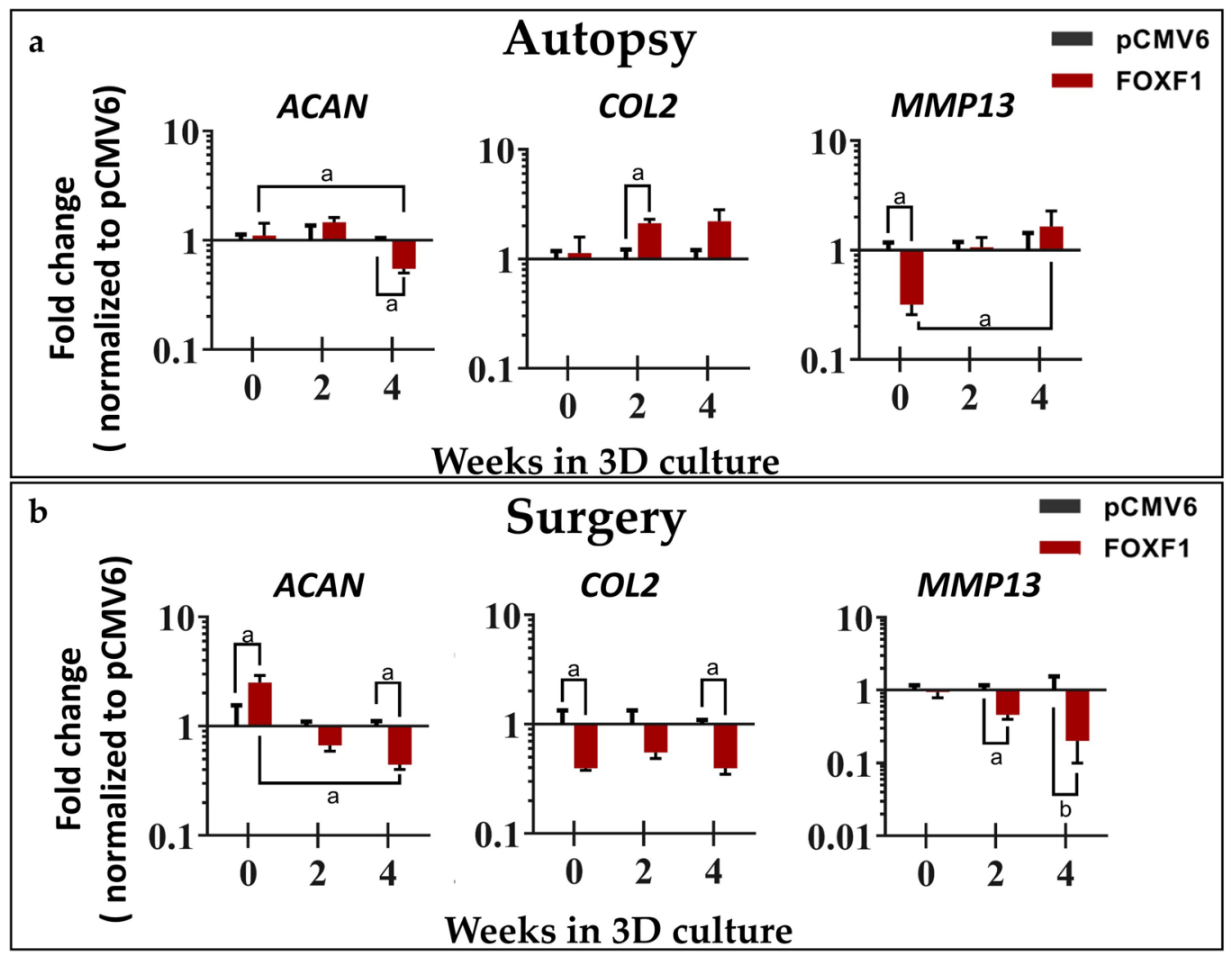

Fig 6. Matrix gene expression for anabolic genes $A C A N$ and $C O L 2$ and catabolic MMP13. (a) Autopsy $(n=5)$ and $(\mathbf{b})$ surgical $(n=5)$ human NP cells at 0,2 , and 4 weeks in 3D agarose culture respectfully normalized to pCMV6 controls and house-keeping gene $18 S$ ( ${ }^{\mathrm{a}} p<0.05,{ }^{\mathrm{b}} p=0.0556$ for FOXF1-treated NP cells as compared to pCMV6 controls). 


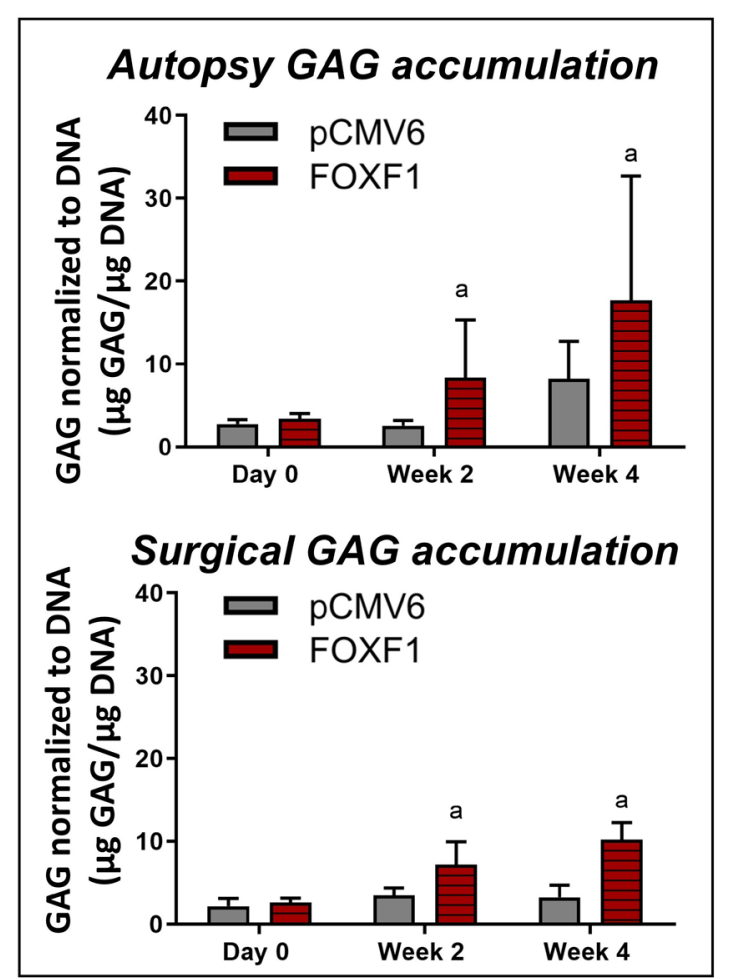

Fig 7. GAG accumulation. Normalized to DNA content of autopsy (top, $n=5$ ) and surgical (bottom, $n=5$ ) human NP cells in 3D culture at 0,2 and 4 weeks ( ${ }^{\mathrm{a}} p<0.05$ for FOXF1-transfected and pCMV6 control).

was upregulated at week 4 (2.59-fold, $p=0.0079)$ in autopsy NP cells, with downregulation in surgical NP cells at day $0(-1.61$-fold, $p=0.0159)$. Lastly, SRY-box transcription factor 9 (SOX9), a chondrocyte marker, showed no significant differences in autopsy NP cells but was upregulated at day 0 (2.56-fold, $p=0.0159)$ in surgical NP cells and downregulated at week 4 $(-4.39, p=0.0079)$ (Fig. 4).

Inflammatory cytokine $I L-1 \beta$ was upregulated in autopsy NP cells at day 0 (3.20-fold, $p=0.0079)$, while significantly downregulated in surgical NP cells at week $2(-2.78$-fold, $p=0.0317)$. Similarly, IL-6 was upregulated at week 4 in autopsy NP cells (1.94fold, $p=0.0079)$ but significantly downregulated at week 2 (-3.73-fold, $p=0.0079)$ in surgical NP cells. No significant differences were observed for TNF- $\alpha$ in either autopsy or surgical NP cells. NGF was significantly downregulated at day 0 (- 2.49-fold, $p=0.0159)$ and week $2(-4.42$-fold, $p=0.0079)$ in surgical NP cells (Fig. 5).

Matrix gene $A C A N$ was downregulated at 4 weeks ( -1.81 -fold, $p=0.238$ ) for autopsy NP cells but was significantly upregulated at day 0 (2.50-fold, $p=0.0476)$ and downregulated at 4 weeks (2.23-fold, $p=0.0079$ ) in surgical NP cells. COL2 was significantly upregulated at week 2 (2.12-fold, $p=0.0159)$ in autopsy NP cells, but significantly downregulated at both day $0(-2.52$-fold, $p=0.0079)$ and week 4 $(-2.51$-fold, $p=0.0079)$ in surgical samples. MMP13 expression was significantly decreased at day 0 (-3.16-fold, $p=0.0079)$ in autopsy NP cells. In surgical cells, MMP13 showed significant downregulation at both $2(-2.17$-fold, $p=0.0317)$ and 4 weeks $(-4.93$ fold, $p=0.0556$ ) (Fig. 6).

\section{GAG content}

No significant differences in GAG content were observed at day 0; however, significantly increased GAG accumulation was observed at week 2 $(8.32 \pm 7.00 \mu \mathrm{g} \mathrm{GAG} / \mu \mathrm{g}$ DNA, $p=0.0413)$ and week 4 $(17.68 \pm 15.05 \mu \mathrm{g}$ GAG/ $\mu \mathrm{g}$ DNA, $p=0.0079)$ in FOXF1transfected autopsy NP cells when compared to pCMV6 controls. Similarly, no significant differences in GAG content were observed at day 0 for surgical NP cells, but significantly increased GAG accumulation was observed at week $2(7.18 \pm 2.68 \mu \mathrm{g} \mathrm{GAG} / \mu \mathrm{g}$ DNA, $p=0.0357)$ and week $4(10.18 \pm 2.06 \mu \mathrm{g}$ GAG/ $\mu \mathrm{gDNA}$, $p=0.0079$ ) in FOXF1-transfected surgical NP groups when compared to pCMV6 controls. No significant difference in raw DNA content was observed (Fig. 7).

\section{Delivery of FOXF1 to IVD cells in vitro and in vivo through engineered EVs Validation of engineered EV generation}

NP cells transfected with FOXF1 demonstrated a significant increase in FOXF1 expression (109.89fold, $p<0.01)$ as compared to NP cells transfected with pCMV6 (Fig. 8a). Similarly, engineered EVs loaded with FOXF1 demonstrated significant increases in FOXF1 expression (4585.63-fold, $p<0.01)$ as compared to EVs loaded with pCMV6, highlighting successful transfection of FOXF1 and loading of engineered EVs with FOXF1. FOXF1- and pCMV6-loaded EVs generated from human NP cells demonstrated significant differences in particle count $\left(5.85 \times 10^{10}\right.$ particles $/ \mathrm{mL}$ and $4.03 \times 10^{10}$ particles/ $\mathrm{mL}$ for FOXF1 and pCMV6, respectively, $p=0.028$ ), with no significant difference in particle size (average $=184 \mathrm{~nm})($ Fig. 8b). Engineered EVs generated from PMEFs and loaded with FOXF1 or pCMV6 for in vivo studies showed no significant difference in either particle count $\left(1.41 \times 10^{11}\right.$ particles/ $\mathrm{mL}$ ) or size distribution, with an average particle size of $282 \mathrm{~nm}$ (Fig. 8c).

\section{Designer EV uptake by NP cells in monolayer}

Brightfield images of NP cells in monolayer were overlaid with fluorescent images of PHK26-stained EVs and the percentage of EV uptake was quantified by the number of cells containing EVs (stained red) over the total number of cells imaged. Combined images demonstrated more than $95 \%$ uptake of stained EVs for both FOXF1 and pCMV6 groups at day 1, 2, and 7, with no significant differences between time points (Fig. 9a). Gene expression for FOXF1 was assessed, with significant upregulation of FOXF1 in cells treated with FOXF1-loaded EVs vs. pCMV6 EVs (control)-treated cells at both day 2 (38.53-fold, $p<0.0286)$ and 7 (15.82-fold, $p<0.0286)$ (Fig. 9b). 
Cell viability in IVDs injected with EVS

Mice IVDs were harvested after euthanasia at $7 \mathrm{~d}$ post-treatment with engineered EVs or saline and stained with Hoechst (blue $=$ DNA) and calcein-AM (green = live cell) to qualitatively assess cell viability. No qualitative differences were observed between injury, pCMV6, and Foxf1-loaded EVs groups, across all isolated discs (Fig. 10a). Due to the high cell density and the 3D structure of the disc, images could not be quantified.

Gene expression in mice discs suggestive of successful EV uptake

RT-qPCR was used to assess gene expression of Foxf1 and Brachyury in discs injected with Foxf1or pCMV6-loaded engineered EVs. Data were normalized to injury controls and the housekeeping gene 18S. Foxf1 was significantly upregulated in disc cells treated with Foxf1-loaded EVs when compared to the injury control group ( $p=0.048)$. Brachyury was also significantly upregulated in disc cells treated with Foxf1-loaded EVs when compared to the injury control group ( $p=0.049$ ). No significant differences were identified in either gene between disc cells treated with pCMV6- loaded EVs and the injury control group $(p>0.05)$ (Fig. 10b). Phenotypic markers, inflammatory cytokines, and matrix markers were also explored for the mice IVDs but no significant differences were found.

\section{Discussion}

The study findings demonstrated that FOXF1 can reprogram human NP cells from autopsy and surgery to a healthier anti-catabolic and anti-inflammatory state. Furthermore, the study also demonstrated that engineered EVs can be used as a non-viral delivery system to deliver transcription factors, such as FOXF1, to human NP cells in vitro and to mouse IVD cells in vivo, with limited cytotoxicity and effective upregulation of genes of interest. The study suggested that harnessing potential developmental transcription factors, such as FOXF1, to reprogram degenerate NP cells back to a healthy state could be a viable therapeutic strategy for treating IVD degeneration and associated discogenic pain. Significant increases in GAG accumulation were observed together with decreased expression of inflammatory cytokines and matrix degradation enzyme, such as MMP13, all hallmarks of a healthy IVD. Furthermore, the study was the first to demonstrate a successful non-viral gene delivery to IVD cells both in vitro and in vivo using engineered EVs, highlighting the potential of this intervention to treat IVD degeneration and discogenic back pain.

Previously, Tang et al. (2019) and Vujovic et al. (2006) have demonstrated the potential of the transcription factor Brachyury to reprogram and regenerate the degenerate IVD due to its elevated

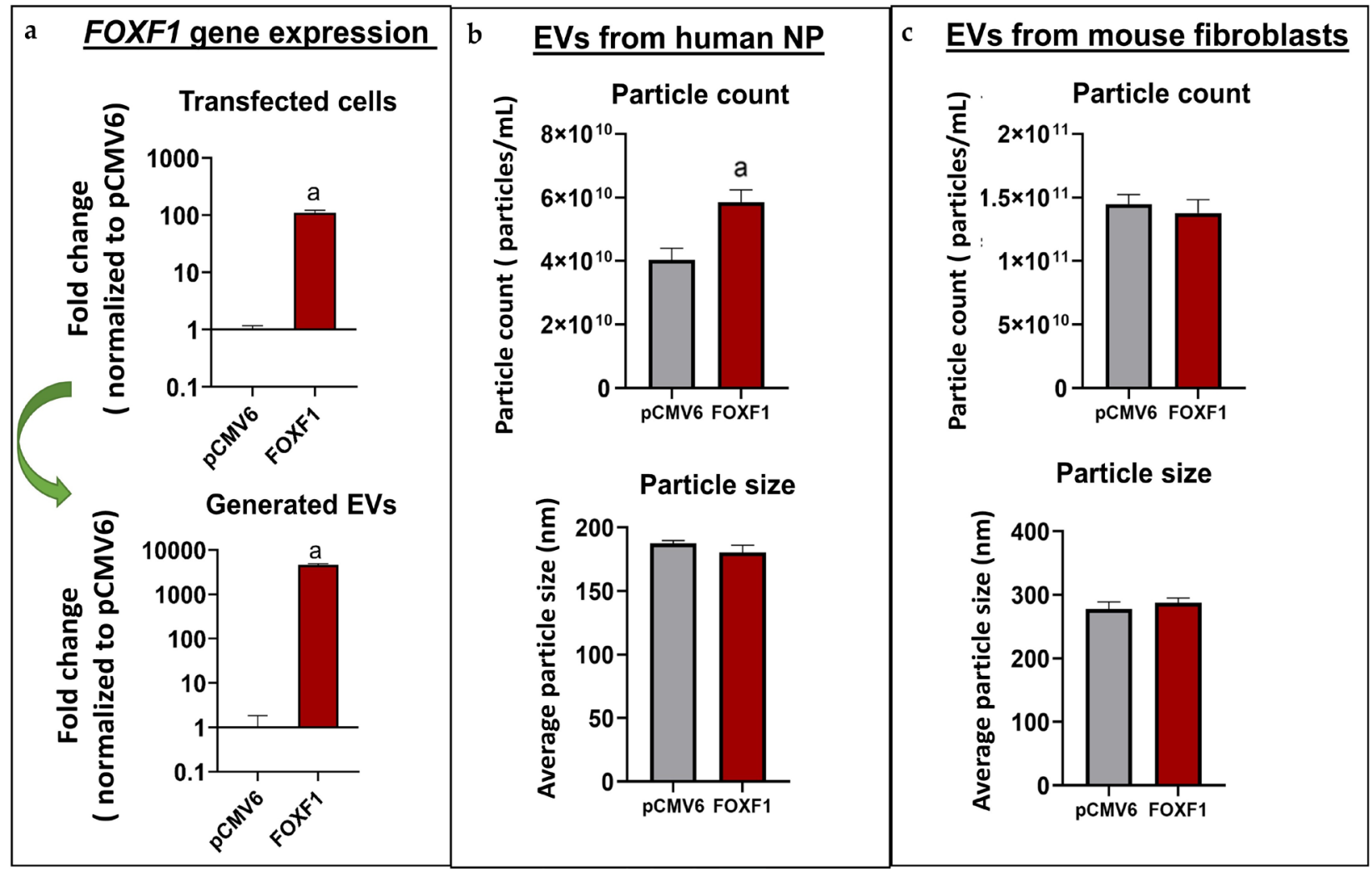

Fig 8. EV characterization. (a) FOXF1 expression in transfected human NP cells (top) and generated EVs (bottom) in FOXF1 groups normalized to pCMV6 $(n=4)$. (b) Average particle count and particle size quantified by NanoSight NS300 for EVs generated from human NP cells. (c) Average particle count and particle size quantified by NanoSight NS300 for EVs generated from mouse embryonic fibroblasts ( $\left.{ }^{\mathrm{a}} p<0.05\right)$. 
levels in the immature healthy NP and its role in notochord development. In the present study, a novel role for FOXF1 was investigated due to its high expression in the healthy NP, its regard as an NP specific marker, and its roles in cell proliferation, differentiation, and growth (Richardson et al., 2017b; Risbud et al., 2015). First, the regenerative potential of FOXF1 was investigated in an in vitro study using bulk electroporation. Assessment of cell viability demonstrated no significant differences between all groups, suggesting that bulk electroporation of FOXF1 or pCMV6 (control) plasmids had no detrimental effects on human NP cells, similar to bulk transfection with Brachyury. Successful transfection of FOXF1 in human NP cells was determined by assessing FOXF1 expression in the transfected human NP cells from autopsy and surgery when compared to pCMV6 controls. FOXF1 was significantly up-regulated at all time-points for autopsy NP cells; however, a more temporal response was observed for surgical NP cells, indicating that FOXF1 was successfully transfected to the NP cells but tissue source and degenerative conditions may affect transfection and reprogramming efficiency. In comparison, bulk electroporation of Brachyury at the same plasmid concentration into autopsy and surgical NP cells showed a much larger fold change ( 100-fold) vs. empty vector controls (Tang et al., 2019). A similar study using bulk electroporation of human MSCs with GDF5 demonstrated upregulation of GDF5 up to 1,000-fold in 3D alginate culture (Bucher et al., 2013). An additional study transfected primary human NP cells with GDF6 and found increased expression of GDF6 over 14 d (May et al., 2017).

With the validation of successful transfection of FOXF1, healthy phenotypic, inflammatory, and neurotrophic markers were also assessed. Brachyury and KRT19 are considered to be healthy NP markers and present in the immature NP; also, the chondrogenic marker SOX9 has been shown to increase matrix production in the human IVD (Lee et al., 2007; Minogue et al., 2010; Paul et al., 2003; Risbud et al., 2015). Therefore, they are excellent candidate markers for assessing successful reprogramming of degenerate NP cells to a healthy NP-like phenotype. Unfortunately, significant upregulation of Brachyury was not observed in either autopsy or surgical cells, with downregulation of Brachyury expression at day 0 in surgical NP cells. Brachyury is a regulator of mesodermal FOXF1 (Zhou et al., 2018) and this has also been demonstrated in human NP cells electroporated with Brachyury (Tang et al., 2019). However, no effect of FOXF1 on Brachyury expression were observed. KRT19 was upregulated at week 4 in

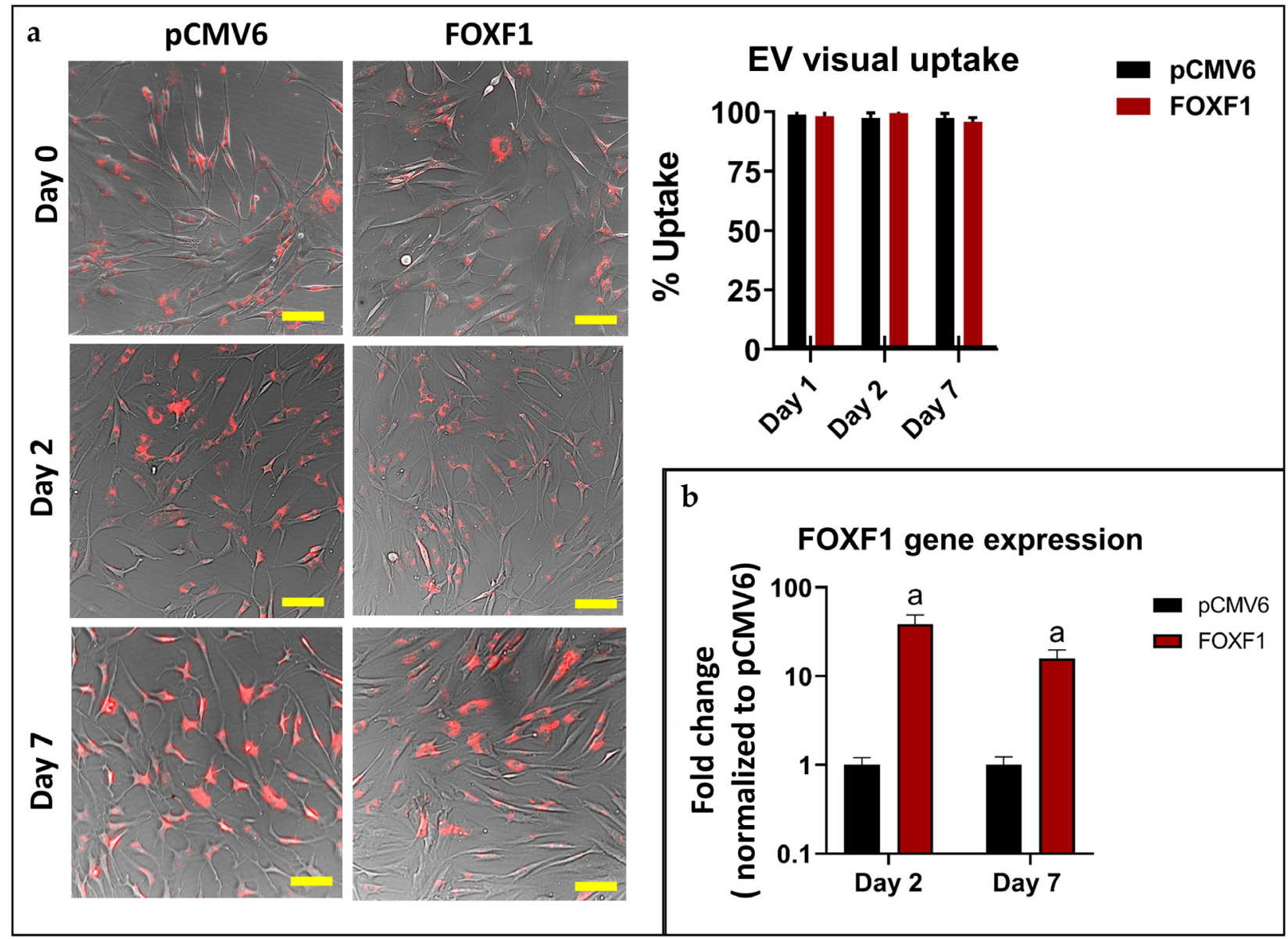

Fig 9. EV uptake by cells. (a) Brightfield images of NP cells co-cultured in monolayer with PKH26-stained pCMV6 and FOXF1 EVs (red) respectively at 0, 2, and $7 \mathrm{~d}$ along with quantified visual uptake by percentage of cells with EVs over total cells. (b) FOXF1 expression of FOXF1-EV-treated human NP cells in monolayer normalized to pCMV6-EV-treated cells ( ${ }^{a} p<0.05$ ). 


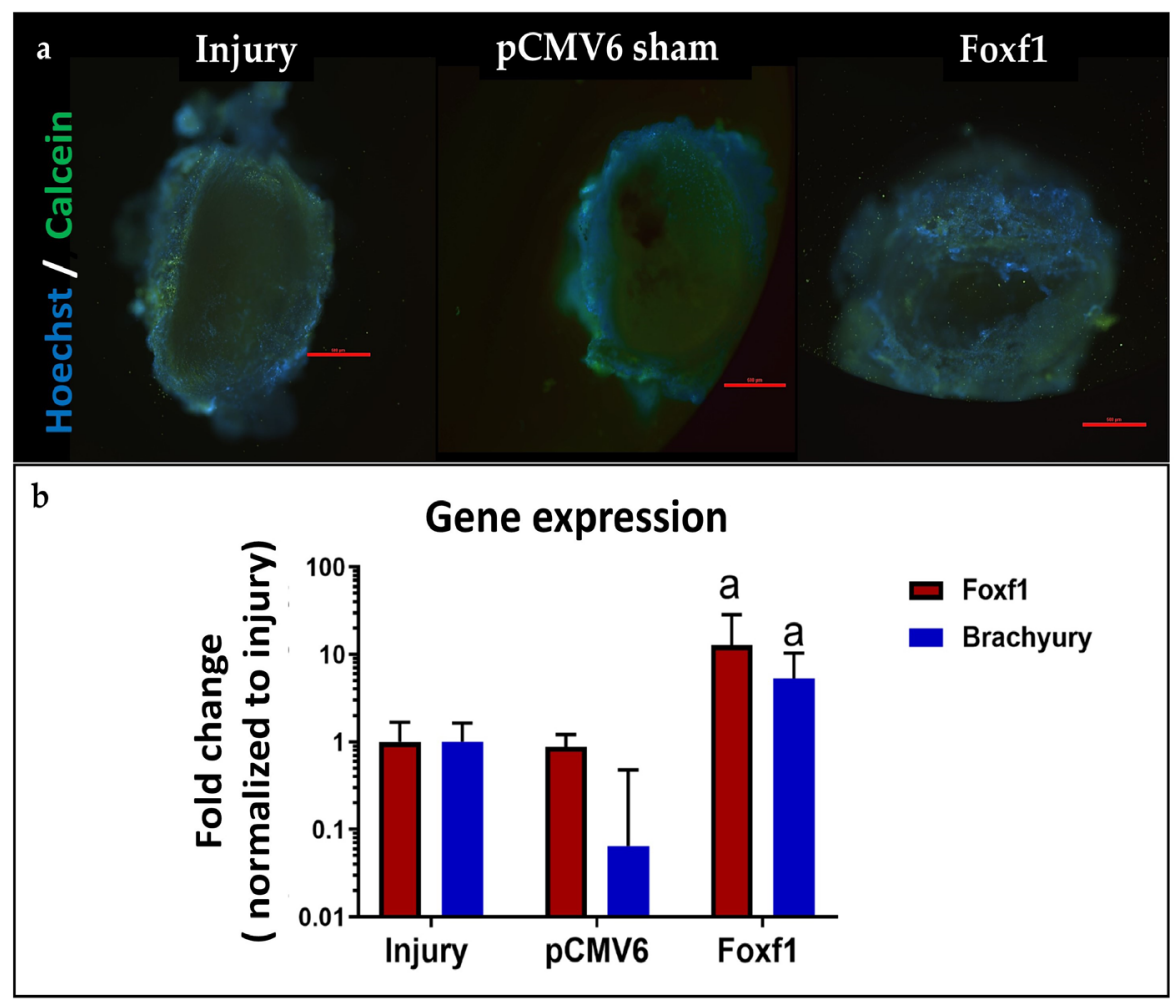

Fig 10. EV uptake by cells. (a) Representative fluorescent images of injury, pCMV6, and Foxf1-EV-treated mouse IVDs dissected post euthanasia and stained with Hoechst (DNA/nucleus) and calceinAM (live/cytosol) (scale bar: 500 nm). (b) Foxf1 and Brachyury expression of mice IVD $7 \mathrm{~d}$ post-injection for Foxf1-and pCMV6-treated mice normalized to injury controls and house-keeping gene $18 S$ ( $\left.{ }^{a} p<0.05\right)$.

autopsy NP cells, with downregulation in surgical NP cells, while SOX9 was upregulated at day 0 for autopsy and surgical NP cells but expression was decreased at both weeks 2 and 4 when compared to controls. This suggested that the effects of FOXF1 transfection from bulk electroporation are transient and that the degree of degeneration between the less degenerate autopsy samples and painful degenerate surgical samples likely influences these effects and transfection efficiency.

IVD degeneration is also characterized by elevated levels of inflammatory cytokines (IL-1 $\beta, I L-6, T N F-\alpha)$ and NGF expression (Freemont et al., 1997; Le Maitre et al., 2007b; Purmessur et al., 2008; Shamji et al., 2010). Therefore, the downregulation of these markers may indicate decreased inflammation and nerve ingrowth. $I L-1 \beta$ and $I L-6$ were downregulated at week 2 and weeks 2 and 4, respectively, in surgical NP cells, yet interestingly upregulated in autopsy NP cells when compared to pCMV6 sham controls. This demonstrated that FOXF1 may downregulate inflammatory cytokines in degenerate NP cells over time, however to a lesser extent in NP cells from autopsy. There were no significant differences in TNF- $\alpha$ expression, suggesting that FOXF1 has minimal effect on TNF- $\alpha$ when compared to PCMV6 controls. Neurotrophic pain marker NGF was downregulated in autopsy NP cells at week 4 and surgical NP cells at day 0 and week 2 , suggesting a reduced ability of NP cells to promote neo-innervation, as nerve ingrowth and NGF are upregulated in painful IVDs (Freemont et al., 2002).

High levels of aggrecan and collagen II are key hallmarks of the healthy NP, however in degeneration, increased ECM degradation and decreased matrix synthesis are observed, leading to a loss of IVD structure and mechanical function (Ghosh, 1988). Therefore, increasing matrix synthesis while decreasing catabolic gene expression is critical for NP regeneration. In the present study, the matrix genes $A C A N$ and COL2 were assessed along with the matrix enzyme MMP13. MMP13 was downregulated at day 0 in autopsy NP cells while downregulated at weeks 2 and 4 in surgical NP cells in FOXF1transfected groups normalized to pCMV6 control, suggesting decreased matrix catabolism in human NP cells. Surprisingly, ACAN was downregulated in autopsy and surgical cells at week 4 and upregulated at day 0 in surgical NP cells only. COL2 exhibited upregulation at week 2 in autopsy NP cells but was consistently downregulated in surgical NP cells. In comparison, on the protein level, GAG accumulation increased in FOXF1-treated groups as compared to pCMV6 at both weeks 2 and 4. As a major hallmark of IVD degeneration is the loss of GAG, increased GAG accumulation is a major indicator of reprogramming success towards a healthy NP phenotype. The inconsistency in gene-level vs. GAG protein measurements could be explained by the temporal nature of RT-qPCR as a snapshot in time, as seen in a previous study (Tang et al., 2019). Notably, May et al. (2017) also found no significant difference in $A C A N$ and COL2 expression after electroporation of GDF6.

Bulk electroporation of FOXF1 into autopsy and surgical NP cells can reprogram human NP cells based on gene-level assessments and notable protein level GAG expression. However, bulk electroporation has limited clinical relevance due to challenges associated with apoptosis, necrosis, and cellular dysfunction of 
cells as well as translation in vivo (Batista Napotnik et al., 2016). For this reason, the present study did not utilize a control (non-bulk-electroporated) group since the aim was to focus only on the effects of FOXF1 on the cells, not bulk electroporation, as it lacks clinical relevance. Thus, a more clinically relevant non-viral gene delivery method was desired and, therefore, engineered EVs were investigated. EVs are nanoscale particles composed of a lipid bilayer membrane that is secreted by all cell types and can carry lipids, proteins, and genetic material, such as RNA and DNA (O'Brien et al., 2020). One of the advantages of using EVs is that they can be derived from a variety of sources in a considerable amount, including many different tissues and biofluids (saliva, plasma, breast milk, urine, cerebrospinal fluid). They have the potential to be produced in large quantities, include cell-specific surface markers of the derivative cell, and are biocompatible and stable for long-term storage (Murphy et al., 2019; O’Brien et al., 2020).

Engineered EVs offer many advantages when compared with other delivery methods - such as synthetic nanocarriers, viral vectors, and non-viral physical and chemical transfection methods including the ability to penetrate biological barriers, to be functionalized for targeted delivery, and pack diverse molecular cargo, improved stability in biofluids and circulation, as well as decreased probability of inducing adverse effects (Gantenbein et al., 2020). Moreover, the therapeutic potential of EVs has been a growing topic of interest and the investigators have previously explored their role in delivery and reprogramming of nerve and blood vessels (Gallego-Perez et al., 2017). In IVD degeneration, EVs derived from MSCs have been investigated mainly in terms of their innate therapeutic potential and delivery of microRNAs such as miR-21 (Cheng et al., 2018; Piazza et al., 2020). However, the potential of non-viral delivery of exogenous transcription factors such as FOXF1 using designer EVs in diseased NP cells remains unexplored.

Bulk electroporation was used to generate FOXF1and sham-loaded designer EVs from human NP cells and primary mouse embryonic fibroblasts. High FOXF1 expression in transfected cells was confirmed followed by validation of effective FOXF1 packing in the engineered EVs. Further characterization of EV size distribution and concentration demonstrated that billions of EV particles were generated from human NP-derived and mouse fibroblast cells and particle size was consistent with the literature. This analysis confirmed that enough EVs were generated for effective treatment of human cells and mice IVDs in vivo. The difference in particle count between pCMV6 and FOXF1 EVs generated from human NP cells could be a potential effect of FOXF1 upregulation in the secretory capacity of transfected cells. This increase in EV production by human NP cells transfected with FOXF1 when compared to the sham may be due to an enhanced secretory capacity of these types of cells when transfected with the transcription factor of interest.

Both FOXF1- and pCMV6-loaded designer EVs tagged with PKH26GL membrane marker demonstrated significantly high levels of uptake in a short-term $7 \mathrm{~d}$ study. As the designer EVs for the human monolayer study were derived from human NP cells, the generated EVs may exhibit preferential uptake by NP cells due to NP membrane specific markers targeted to NP cells. This highlights the potential advantage of non-viral gene delivery through designer EVs but needs to be validated in future studies. Analysis of gene expression for the FOXF1-loaded EV group showed significant overexpression of FOXF1 at day 2 and 7 when compared to pCMV6 EVs, indicating successful and highly effective delivery of FOXF1 into NP cells. Notably, EVs have also shown attraction and binding to fibronectin and collagen type I, alluding to potential retention in IVD tissue (Narayanan et al., 2016). As far as it can be ascertained, there are no other reports describing the non-viral delivery of molecular cargo to the IVD through designer EVs. Other studies have assessed the content and function of non-engineered IVD-derived, MSC-derived, or notochordal-cellderived EVs for treatment of IVD degeneration and these particular EVs have also been assessed as disease biomarkers (e.g. microRNAs) (Bach et al., 2017; Chen et al., 2018; Park et al., 2019). As cell survival and functionality may limit the therapeutic potential of MSC treatments, recent literature has focused on the use of MSC-derived EVs for the reversal of disc degeneration (Huang et al., 2013; Park et al., 2019). These studies highlight the potential of EVs therapies as a novel therapeutic strategy to target low-back pain and IVD degeneration.

To assess the delivery of Foxf1 to IVD tissue in vivo using mouse embryonic fibroblast-derived designer EVs, a pilot study using a mouse lumbar disc injury model was performed and viability, including transcription factor expression, determined at $7 \mathrm{~d}$. Hoechst and calcein-AM staining of mice lumbar IVDs found no qualitative differences in IVD cell viability, suggesting that the engineered EVs have minimal cytotoxic effects on the IVD. Upregulation of Foxf1 was observed in mice discs treated with Foxf1-loaded EVs as compared to those treated with pCMV6-loaded EVs and injury controls. This suggested that Foxf1 was successfully delivered to the disc and expressed for at least $7 \mathrm{~d}$, but further work is required to quantify the efficiency of EV uptake and confirm Foxf1 protein expression within the disc. Interestingly, Brachyury was also upregulated in Foxf1-treated groups indicating that Foxf1 may have a regulatory role on Brachyury unlike the observations for in vitro bulk transfection of FOXF1. Other phenotypic markers such as KRT19, along with inflammatory cytokines and matrix gene expression showed no significant differences between Foxf1- 
treated groups and controls, suggesting the need for more replicates as only $N=3$ were used for the pilot study. These differences in effects between the in vitro and in vivo models may be attributed to several factors, for example electroporation vs. EV delivery, human vs. mouse, or the nature of an isolated in vitro model vs. a more complex in vivo microenvironment.

Delivery of Foxf1 through engineered EVs showed successful transport of Foxf1 and gene expression in vivo over $7 \mathrm{~d}$. However, longer-term in vivo studies are required to validate the safety, efficacy, and clinical potential of this strategy for the degenerate IVD and DBP. For example, exploration of several relevant inflammatory cytokines, as discussed in the in vitro studies, along with structure/function and pain behaviors. Furthermore, cells from female IVD specimens were used for the monolayer studies while male mice were used for in vivo studies and sex differences have been reported to be important when assessing therapeutic potential candidate targets (Mosley et al., 2019; Richards et al., 2019). Future studies will focus on the long-term therapeutic effects of transcription factor encased EVs with sex differences included as a factor in the analysis. In addition, further pre-clinical validation using engineered EVs with transcription factors as a therapeutic strategy for IVD degeneration and lowback pain is warranted in clinically relevant large animal models such as the chondrodystrophic canine.

\section{Conclusions}

This is the first study to demonstrate the therapeutic potential of the developmental transcription factor FOXF1 to reprogram human NP cells towards a healthy NP-like phenotype as demonstrated by enhanced expression of NP phenotypic markers, decreased catabolism/inflammation, and GAG accumulation using non-viral methods. Furthermore, the potential of engineered EVs to effectively deliver a plasmid encoding FOXF1 to NP cells was shown both in monolayer in vitro, and in mice lumbar IVDs in vivo. This approach has high clinical relevance as it is minimally invasive, non-addictive, non-viral and has the potential to reprogram native degenerate IVD cells in situ for the treatment of discogenic back pain.

\section{Acknowledgments}

Financial support for the study was provided by The Ohio State University, Department of Biomedical Engineering, National Institutes of Health: R61AR076786, the ON/ORS KickStarter Grant and the Ohio State University Center for Clinical and Translational Science/NCATS: UL1TR002733. The investigators would like to thank Gilian Gunsch, Tiffany Ko, Connor Gannt, Kyle Kuchynsky, Jordan More, Gina P. Guio-Vega, Kiana Poole, the OSU
Genomics Core and ULAR Staff for their technical assistance.

\section{References}

Bach F, Libregts S, Creemers L, Meij B, Ito K, Wauben M, Tryfonidou M (2017) Notochordal-cell derived extracellular vesicles exert regenerative effects on canine and human nucleus pulposus cells. Oncotarget 8: 88845-88856.

Balagué F, Mannion AF, Pellisé F, Ciedraschi C (2012) Non-specific low back pain. Lancet 379: 482491.

Batista Napotnik T, Reberšek M, Vernier PT, Mali B, Miklavčič D (2016) Effects of high voltage nanosecond electric pulses on eukaryotic cells (in vitro): a systematic review. Bioelectrochemistry 110: 1-12.

Bolte C, Flood HM, Xiaomeng R, Jagannathan S, Artem B, Kalin TV, Kalinichenko VV (2017) FOXF1 transcription factor promotes lung regeneration after partial pneumonectomy. Sci Rep 7: 1-14.

Bucher C, Gazdhar A, Benneker LM, Geiser T, Gantenbein-Ritter B (2013) Nonviral gene delivery of growth and differentiation factor 5 to human mesenchymal stem cells injected into a 3D bovine intervertebral disc organ culture system. Stem Cells Int. 2013: 1-9.

Cao F, Xie X, Gollan T, Zhao L, Narsinh K, Lee RJ, $\mathrm{Wu}$ JC (2010) Comparison of gene-transfer efficiency in human embryonic stem cells. Mol Imaging Biol 12: 15-24.

Chen Y, Tang Y, Fan GC, Duan DD (2018) Extracellular vesicles as novel biomarkers and pharmaceutic targets of diseases. Acta Pharmacol Sin 39: 499-500.

Cheng X, Zhang G, Zhang L, Hu Y, Zhang K, Sun X, Zhao C, Li H, Li YM, Zhao J (2018) Mesenchymal stem cells deliver exogenous miR-21 via exosomes to inhibit nucleus pulposus cell apoptosis and reduce intervertebral disc degeneration. J Cell Mol Med 22: 261-276.

Deyo RA, Von Korff M, Duhrkoop D (2015) Opioids for low back pain. BMJ 350: g6380-g6380.

Duarte-Sanmiguel S, Higuita-Castro N, GallegoPerez D (2020) Nanoelectroporation and collection of genetically modified exosomes in primary cultures of dendritic cells. Methods Mol Biol 2050: 79-84.

Flood HM, Bolte C, Dasgupta N, Sharma A, Zhang Y, Gandhi CR, Kalin TV, Kalinichenko VV (2019) The Forkhead box F1 transcription factor inhibits collagen deposition and accumulation of myofibroblasts during liver fibrosis. Biol Open 8: bio039800. DOI: 10.1242/bio.039800.

Freemont AJ (2008) The cellular pathobiology of the degenerate intervertebral disc and discogenic back pain. Rheumatology 48: 5-10.

Freemont AJ, Peacock TE, Goupille P, Hoyland JA, O'Brien J, Jayson MIV (1997) Nerve ingrowth 
into diseased intervertebral disc in chronic back pain. Lancet 350: 178-181.

Freemont AJ, Watkins A, Le Maitre C, Baird P, Jeziorska M, Knight MTN, Ross ERS, O'Brien JP, Hoyland JA (2002) Nerve growth factor expression and innervation of the painful intervertebral disc. J Pathol 197: 286-292.

Gallego-Perez D, Pal D, Ghatak S, Malkoc V, Higuita-Castro N, Gnyawali S, Chang L, Liao W, Shi J, Sinha M, Singh K, Steen E, Sunyecz A, Stewart R, Moore J, Ziebro T, Northcutt RG, Homsy M, Bertani P, Lu W, Roy S, Khanna S, Rink C, Sundaresan VB, Otero JJ, Lee LJ, Sen CK (2017) Topical tissue nano-transfection mediates non-viral stroma reprogramming and rescue. Nat Nanotechnol 12: 974-979.

Gantenbein B, Tang SN, Guerrero J, HiguitaCastro N, Salazar-Puerta A, Croft A, Gazdhar A, Purmessur D (2020) Non-viral gene delivery methods for bone \& joints. Front Bioeng Biotechnol 8: 598466. DOI: $10.3389 /$ fbioe.2020.598466.

Ghosh P (1988) The Biology of the Intervertebral disc. Volume 2, 1st edition. Boca Raton, FL, USA. CRC Press.

Global Burden of Disease Study 2013 Collaborators (2015) Global, regional, and national incidence, prevalence, and years lived with disability for 301 acute and chronic diseases and injuries in 188 countries, 1990-2013: a systematic analysis for the Global Burden of Disease Study 2013. Lancet 386: 743-800.

Ha D, Yang N, Nadithe V (2016) Exosomes as therapeutic drug carriers and delivery vehicles across biological membranes: current perspectives and future challenges. Acta Pharm Sin B 6: 287-296.

Huang YC, Leung VYL, Lu WW, Luk KDK (2013) The effects of microenvironment in mesenchymal stem cell-based regeneration of intervertebral disc. Spine J 13: 352-362.

de Jong OG, Verhaar MC, Chen Y, Vader P, Gremmels H, Posthuma G, Schiffelers RM, Gucek M, van Balkom BWM (2012) Cellular stress conditions are reflected in the protein and RNA content of endothelial cell-derived exosomes. J Extracell Vesicles 1. DOI: $10.3402 /$ jev.v1i0.18396.

Karagiannis P, Yamanaka S (2014) The fate of cell reprogramming. Nat Methods 11: 1006-1008.

Katz JN (2006) Lumbar disc disorders and lowback pain: socioeconomic factors and consequences. J Bone Jt Surg 88 Suppl 2: 21-24.

Lama P, Le Maitre CL, Harding IJ, Dolan P, Adams MA (2018) Nerves and blood vessels in degenerated intervertebral discs are confined to physically disrupted tissue. J Anat 233: 86-97.

Lee CR, Sakai D, Nakai T, Toyama K, Mochida J, Alini M, Grad S (2007) A phenotypic comparison of intervertebral disc and articular cartilage cells in the rat. Eur Spine J 16: 2174-2185.

Livak KJ, Schmittgen TD (2001) Analysis of relative gene expression data using real-time quantitative PCR and the $2^{-\triangle \Delta C T}$ method. Methods 25: 402-408.
Loibl M, Wuertz-Kozak K, Vadala G, Lang S, Fairbank J, Urban JP (2019) Controversies in regenerative medicine: should intervertebral disc degeneration be treated with mesenchymal stem cells? JOR Spine 2: e1043. DOI: 10.1002/jsp2.1043.

Le Maitre CL, Pockert A, Buttle DJ, Freemont AJ, Hoyland JA (2007a) Matrix synthesis and degradation in human intervertebral disc degeneration. Biochem Soc Trans 35: 652-655.

Le Maitre C, Hoyland J, Freemont AJ (2007b) Catabolic cytokine expression in degenerate and herniated human intervertebral discs: IL-1 $\beta$ and TNF- $\alpha$ expression profile. Arthritis Res Ther 9: R77. DOI: 10.1186/ar2275.

Malik K, Cohen S, Walega D, Benzon H (2013) Diagnostic criteria and treatment of discogenic pain: a systematic review of recent clinical literature. Spine J 13: 1675-1689.

Mauck RL, Seyhan SL, Ateshian GA, Hung CT (2002) Influence of seeding density and dynamic deformational loading on the developing structure/ function relationships of chondrocyte-seeded agarose hydrogels. Ann Biomed Eng 30: 1046-1056.

May RD, Tekari A, Frauchiger DA, Krismer A, Benneker LM, Gantenbein B (2017) efficient nonviral transfection of primary intervertebral disc cells by electroporation for tissue engineering application. Tissue Eng. Part C Methods 23: 30-37.

Minogue BM, Richardson SM, Zeef LAH, Freemont AJ, Hoyland JA (2010) Characterization of the human nucleus pulposus cell phenotype and evaluation of novel marker gene expression to define adult stem cell differentiation. Arthritis Rheum 62: 3695-3705.

Mosley GE, Hoy RC, Nasser P, Kaseta T, Lai A, Evashwick-Rogler TW, Lee M, Iatridis JC (2019) Sex differences in rat intervertebral disc structure and function following annular puncture injury. Spine (Phila Pa 1976) 44: 1257-1269.

Mulcahy LA, Pink RC, Carter DRF (2014) Routes and mechanisms of extracellular vesicle uptake. J Extracell Vesicles 3: 24641. DOI: 10.3402/jev.v3.24641.

Murphy DE, de Jong OG, Brouwer M, Wood MJ, Lavieu G, Schiffelers RM, Vader P (2019) Extracellular vesicle-based therapeutics: natural versus engineered targeting and trafficking. Exp Mol Med 51: 1-12.

Narayanan R, Huang C-C, Ravindran S (2016) Hijacking the cellular mail: exosome mediated differentiation of mesenchymal stem cells. Stem Cells Int 2016: 1-11.

O’Brien K, Breyne K, Ughetto S, Laurent LC, Breakefield XO (2020) RNA delivery by extracellular vesicles in mammalian cells and its applications. Nat Rev Mol Cell Biol 21: 585-606.

Okita K, Nakagawa M, Hyenjong H, Ichisaka T, Yamanaka S (2008) Generation of mouse induced pluripotent stem cells without viral vectors. Science 322: 949-953.

Park KS, Bandeira E, Shelke G V., Lässer C, Lötvall J (2019) Enhancement of therapeutic potential of mesenchymal stem cell-derived extracellular vesicles. 
Stem Cell Res Ther 10: 288. DOI: 10.1186/s13287-0191398-3.

Paul R, Haydon RC, Cheng H, Ishikawa A, Nenadovich N, Jiang W, Zhou L, Breyer B, Feng T, Gupta P, He TC, Phillips FM (2003) Potential use of Sox9 gene therapy for intervertebral degenerative disc disease. Spine (Phila Pa 1976). 28: 755-763.

Piazza N, Dehghani M, Gaborski TR, WuertzKozak K (2020) Therapeutic potential of extracellular vesicles in degenerative diseases of the intervertebral disc. Front Bioeng Biotechnol 8: 1-8.

Purmessur D, Freemont AJ, Hoyland JA (2008) Expression and regulation of neurotrophins in the nondegenerate and degenerate human intervertebral disc. Arthritis Res Ther 10: 1-9.

Richards J, Tang S, Gunsch G, Sul P, Wiet M, Flanigan DC, Khan SN, Moore S, Walter B, Purmessur D (2019) Mast cell/proteinase activated receptor 2 (PAR2) mediated interactions in the pathogenesis of discogenic back pain. Front Cell Neurosci 13: 294. DOI: 10.3389/fncel.2019.00294.

Richardson SM, Ludwinski FE, Gnanalingham KK, Atkinson RA, Freemont AJ, Hoyland JA (2017a) Notochordal and nucleus pulposus marker expression is maintained by sub-populations of adult human nucleus pulposus cells through aging and degeneration. Sci Rep 7: 1-11.

Richardson SM, Ludwinski FE, Gnanalingham KK, Atkinson RA, Freemont AJ, Hoyland JA (2017b) Notochordal and nucleus pulposus marker expression is maintained by sub-populations of adult human nucleus pulposus cells through aging and degeneration. Sci Rep 7: 1501. DOI: 10.1038/s41598017-01567-w.

Risbud MV, Schoepflin ZR, Mwale F, Kandel RA, Grad S, Iatridis JC, Sakai D, Hoyland JA (2015) Defining the phenotype of young healthy nucleus pulposus cells: recommendations of the Spine Research Interest Group at the 2014 annual ORS meeting. J Orthop Res 33: 283-293.

Schwarzer AC, Aprill CN, Derby R, Fortin J, Kine G, Bogduk N (1995) The prevalence and clinical features of internal disc disruption in patients with chronic low back pain. Spine (Phila Pa 1976). 20: 18781883.

Shamji MF, Setton LA, Jarvis W, So S, Chen J, Jing L, Bullock R, Isaacs RE, Brown C, Richardson WJ (2010) Proinflammatory cytokine expression profile in degenerated and herniated human intervertebral disc tissues. Arthritis Rheum 62: 1974-1982.

Shi C, Das V, Li X, Kc R, Qiu S, O-Sullivan IS, Ripper RL, Kroin JS, Mwale F, Wallace AA, Zhu B, Zhao L, van Wijnen AJ, Ji M, Lu J, Votta-Velis G, Yuan W, Im HJ (2018) Development of an in vivo mouse model of discogenic low back pain. J Cell Physiol 233: 6589-6602.

Smith LJ, Nerurkar NL, Choi K-S, Harfe BD, Elliott DM (2011) Degeneration and regeneration of the intervertebral disc: lessons from development. Dis Model Mech 4: 31-41.
Sobajima S, Kim J, Gilbertson L, Kang J (2004) Gene therapy for degenerative disc disease. Gene Ther 11: 390-401.

Stankiewicz P, Sen P, Bhatt SS, Storer M, Xia Z, Bejjani BA, Ou Z, Wiszniewska J, Driscoll DJ, Bolivar J, Bauer M, Zackai EH, McDonald-McGinn D, Nowaczyk MMJ, Murray M, Shaikh TH, Martin V, Tyreman M, Simonic I, Willatt L, Paterson J, Mehta S, Rajan D, Fitzgerald T, Gribble S, Prigmore E, Patel A, Shaffer LG, Carter NP, Cheung SW, Langston C, Shaw-Smith C (2009) Genomic and genic deletions of the fox gene cluster on 16q24.1 and inactivating mutations of FOXF1 cause alveolar capillary dysplasia and other malformations. Am J Hum Genet 85: 537-537.

Stoorvogel W, Kleijmeer MJ, Geuze HJ, Raposo G (2002) The biogenesis and functions of exosomes. Traffic 3: 321-330.

Takahashi K, Yamanaka S (2006) Induction of pluripotent stem cells from mouse embryonic and adult fibroblast cultures by defined factors. Cell 126: 663-676.

Tang S, Richards J, Khan S, Hoyland J, GallegoPerez D, Higuita-Castro N, Walter B, Purmessur D (2019) Nonviral transfection with brachyury reprograms human intervertebral disc cells to a proanabolic anti-catabolic/inflammatory phenotype: a proof of concept study. J Orthop Res 37: 2389-2400.

Thompson JP, Pearce RH, Schechter MT, Adams ME, Tsang IK, Bishop PB (1990) Preliminary evaluation of a scheme for grading the gross morphology of the human intervertebral disc. Spine (Phila Pa 1976) 15: 411-415.

Trout JJ, Buckwalter J a, Moore KC (1982a) Ultrastructure of the human intervertebral disc: II. Cells of the nucleus pulposus. Anat Rec 204: 307-314.

Trout JJ, Buckwalter JA, Moore KC, Landas SK (1982b) Ultrastructureofthe human intervertebral disc. I. Changes in notochordal cells with age. Tissue Cell 14: 359-369.

Tuteja G, Kaestner KH (2007) SnapShot: forkhead transcription factors I. Cell 130: 1160. DOI: 10.1016/j. cell.2007.09.005.

Vadalà G, Russo F, Ambrosio L, Loppini M, Denaro V (2016) Stem cells sources for intervertebral disc regeneration. World J Stem Cells 8: 185-201.

Valadi H, Ekström K, Bossios A, Sjöstrand M, Lee JJ, Lötvall JO (2007) Exosome-mediated transfer of mRNAs and microRNAs is a novel mechanism of genetic exchange between cells. Nat Cell Biol 9: 654659.

Vo NV, Hartman RA, Patil PR, Risbud M V., Kletsas D, Iatridis JC, Hoyland JA, Le Maitre CL, Sowa GA, Kang JD (2016) Molecular mechanisms of biological aging in intervertebral discs. J Orthop Res 34: 1289-1306. DOI: 10.1002/jor.23195.

Vujovic S, Henderson S, Presneau N, Odell E, Jacques T, Tirabosco R, Boshoff C, Flanagan A (2006) Brachyury, a crucial regulator of notochordal development, is a novel biomarker for chordomas. J Pathol 209: 157-165. 
Zhao L, Manchikanti L, Kaye AD, Abd-Elsayed A (2019) Treatment of discogenic low back pain: current treatment strategies and future options - a literature review. Curr Pain Headache Rep 23: 86. DOI: 10.1007/ s11916-019-0821-x.

Zhou J, Plagge A, Murray P (2018) Functional comparison of distinct Brachyury+ states in a renal differentiation assay. Biol Open 7: 31799. DOI: 10.1242/bio.031799.

\section{Discussion with Reviewers}

Laura Creemers: What is the clinical feasibility of EVs with respect to issues such as upscaling and quality control?

Authors: This is a very important point as upscaling production of engineered EVs may require optimization of isolation methods that can handle significantly larger volume samples and defining effective parameters for verification of reproducibility between batches in terms of EV yield, size distribution and content. One of the advantages of using EVs is that they can be derived from a variety of sources in a considerable amount, including many different tissues and biofluids (saliva, plasma, breast milk, urine, cerebrospinal fluid). Additionally, their content can be analyzed using different characterization methods, such as RT-qPCR to evaluate their mRNA or DNA content, Western Blot and enzyme-linked immunosorbent assay (ELISA) to detect the presence of specific proteins, and nanoparticle tracking analysis to determine their size and concentration, among others. In general, EVs are considered to be stable in fluids and capable of being frozen for later use.

Victor Leung: How far can EVs diffuse comparing to growth factors or other biologics in tissue? How does it compare to virus transduction in terms of cell uptake efficiency? As mouse disc is much smaller than human disc, do you think EV would be as effective for clinical application?

Authors: Growth factors, while potent, generally have shorter half-lives while our goal is to use direct cellular reprogramming in order to drive the diseased cells towards a healthy state. Future studies need to focus on evaluating the EVs ability to effectively diffuse and "transduce" target cells in larger pre-clinical or clinical models of this condition, as well as to benchmark this novel non-viral delivery approach of using engineered EVs to established viral transfection methods. Mice discs are significantly different from human discs in cellularity and size. However, it is an appropriate model to assess initial therapeutic potential before moving on to larger pre-clinical models that better mimic the human pathophysiology, such as the chondrodystrophic canine who also experiences spontaneous low-back pain.

Editor's note: The Scientific Editor responsible for this paper was Sibylle Grad. 